\title{
The influence of roadside vegetation barriers on airborne nanoparticles and pedestrians exposure under varying wind conditions
}

\author{
Abdullah N. Al-Dabbous ${ }^{1}$ and Prashant Kumar ${ }^{1,2, *}$ \\ ${ }^{1}$ Department of Civil and Environmental Engineering, Faculty of Engineering and Physical \\ Sciences (FEPS), University of Surrey, Guildford GU2 7XH, United Kingdom \\ ${ }^{2}$ Environmental Flow (EnFlo) Research Centre, FEPS, University of Surrey, Guildford GU2 \\ 7XH, United Kingdom
}

\begin{abstract}
Roadside vegetation barriers are used in many urban areas to restrict air and noise pollution from reaching roadside pedestrians, but their effectiveness in limiting the movement of nanoparticles is not yet known. This study investigates the influence of a roadside vegetation barrier on particle number distribution (PND) and concentration (PNC) and associated exposure under different wind directions. Size-resolved particles in the 5-560 $\mathrm{nm}$ size range were measured along a busy roadside in Guildford (Surrey, UK) using a fast response differential mobility spectrometer (DMS50). A custom-built solenoid switching system, together with the DMS50, was used to make sequential measurements at the front $\left(L_{2}\right)$, middle $\left(L_{3}\right)$ and back $\left(L_{4}\right)$ of the vegetation barrier; $L_{1}$ was in parallel to $L_{2}$ at a vegetationfree location. Measured data were divided into the three predominant wind directions: crossroad (NW-SW), cross-footpath (NE-SE) and along-road (NW-NE). The consistency in the shape of PNDs and the corresponding geometric mean diameters at the three sites $\left(L_{2}, L_{3}, L_{4}\right)$ indicate an identical removal effect of vegetation barrier for all size of particles. Comparison of the PNCs at two parallel locations (with and without the vegetation barrier) showed $\sim 11 \%$ higher PNCs $\left(1.99 \pm 1.77 \times 10^{5} \mathrm{~cm}^{-3}\right)$ at $L_{2}$ than those at $L_{1}$ during cross-road winds, showing the impeding effect of the vegetation barrier. Such differences were insignificant during the remaining wind directions. Cross-road winds indicate the effect of vegetation barrier; the PNCs were decreased by 14 and $37 \%$ at $L_{3}$ and $L_{4}$, respectively, compared with $L_{2}$. During cross-footpath winds, particles were carried away by the wind from the sampling location.
\end{abstract} Significant decrease in PNCs were consequently seen at $L_{3}\left(1.80 \pm 1.01 \times 10^{4} \mathrm{~cm}^{-3}\right)$ and $L_{4}$

"Corresponding author: Address as above; Tel. +44 1483 682762; Fax: +44 1483 682135; Email addresses: $\underline{\text { P.Kumar@ } \text { surrey.ac.uk, Prashant.Kumar@cantab.net }}$

Cite this article as: Al-Dabbous, A.N., Kumar, P., 2014. The influence of roadside vegetation barriers on airborne nanoparticles and pedestrians exposure under varying wind condition. Atmospheric Environment 90 , 113-124. Online Link: http://dx.doi.org/10.1016/j.atmosenv.2014.03.040 
$\left(1.49 \pm 0.91 \times 10^{4} \mathrm{~cm}^{-3}\right)$ compared with $L_{2}\left(6.26 \pm 3.31 \times 10^{4} \mathrm{~cm}^{-3}\right)$. The PNCs at these locations showed modest differences during the cross-footpath and along-road winds. Respiratory deposited doses (RDD) at $L_{4}$ were found to be the lowest during all wind directions compared with the $L_{1}-L_{3}$. The vegetation barrier efficiently reduced the RDD by $\sim 36 \%$ during crossroad winds. Our results show the mitigation potential of vegetation barriers in limiting nearroad nanoparticles exposure and the measured data can facilitate performance evaluation of theoretical models.

Key words: Particle number concentration; Particle size distribution; Nanoparticles; Roadside vegetation barrier; Traffic emissions; Respiratory deposited doses

\section{INTRODUCTION}

Recent research has demonstrated an association between the airborne nanoparticles (particles with diameters below $300 \mathrm{~nm}$, which represent the majority of particle number concentrations, PNCs) and adverse effects on human health (Bakand et al., 2012) and urban visibility (Stjern et al., 2011). Airborne nanoparticles also influence the optical properties of coarse particles by depositing on their surfaces due to coagulation and thereby contributing to global radiation balance (Buseck and Adachi, 2008). These adverse effects call for the need to control the emissions of nanoparticles, both at the source and the receptor (Kumar et al., 2011a). Emission mitigation measures in the form of technological improvements, reduction in fuel sulphur content and the Euro 5 and Euro 6 vehicle emission standards (EC, 2008) have reduced the nanoparticle emissions from the vehicles in Europe (Jones et al., 2012). In Europe, road transport emissions contributed over $60 \%$ of the total particle number emissions in 2010 (Kumar et al., 2014) and this contribution can be up to $90 \%$ along the roadsides in polluted urban environments (Kumar et al., 2010). The assessment of the mitigation potential of the near-road vegetation barriers is therefore important to understand their effectiveness in reducing the exposure of roadside footpath dwellers.

Vegetation barriers along the heavy traffic roadsides can also reduce the traffic-induced pollution from reaching the receptors such as roadside pedestrians. Recent studies have, however, suggested that the presence of vegetation in street canyons can enhance the pollutant concentrations by obstructing the flow and trapping the pollutants (Vos et al., 2013). In terms of busy roadsides in open areas, vegetation barriers have been found to be beneficial in improving the near-road air quality (Heist et al., 2009; Baldauf et al., 2011). These have 
been reported to reduce the pollutant concentrations due to enhanced turbulence and initial mixing/dilution (Bowker et al., 2007) and deposition of particles on tree leaves and bark (AdabtOakland, 2013). As highlighted by Baldauf et al. (2011), detailed investigations are needed in order to understand the effectiveness of vegetation barriers under a number of factors such as their long-term assessment during varying meteorological and vegetation state conditions, interactions with traffic-induced pollution, and effectiveness under varying traffic emission and road configuration. The case for nanoparticles is even less encouraging since the efficiency of vegetation barriers in removing them is nearly unknown, and comprehensive modelling and field studies for optimising their design are therefore needed (Baldauf et al., 2013).

A few monitoring and modelling studies have investigated the influence of roadside barriers on various types of pollutants, but studies referring to PNC are, so far, rare (see summary of relevant studies in Table 1). For instance, field measurements by Baldauf et al. (2008) assessed the impact of noise barrier (with and without the vegetation) on air quality near a busy highway in Raleigh, North Carolina. They found an average reduction of $20 \%$ in PNCs behind the noise barrier compared to what was measured in open field without the noise barrier. This work also found that the combination of noise and vegetation barriers reduced the PNCs more efficiently than the noise barrier alone. Likewise, Hagler et al. (2012) studied the effect of both the brick-made noise barrier and vegetation barrier on the PNCs. They found that the PNC measured at $10 \mathrm{~m}$ from the road were $\sim 50 \%$ lower behind the brick noise wall relative to a nearby location without a barrier. The effect of vegetation barrier on the PNC was, however, found to be inconclusive. Maher et al. (2013) studied the effect of outdoor tree lines on indoor concentrations of $\mathrm{PM}_{10}, \mathrm{PM}_{2.5}$ and $\mathrm{PM}_{1}$ (particulate matter with cut-off aerodynamic diameter less than $10,2.5$ and $1 \mu \mathrm{m}$, respectively). They found that screening of the houses by the tree lines reduces more than $50 \%$ of particulate matter inside the houses. The SEM (Scanning Electron Micrographs) analysis of the tree leafs showed that over $60 \%$ of the particles deposited were in nano-size range. Furthermore, Brantley et al. (2014) studied the effect of vegetation barrier on near-road black carbon and particles in the size range of 500 to $10000 \mathrm{~nm}$ under varying wind directions. They reported up to $22 \%$ reduction in black carbon concentrations behind the vegetation barrier but no such reductions in PNCs were noted. Bowker et al. (2007) modelled the effect of roadside barriers on the PNCs using Quick Urban and Industrial Complex (QUIC) model. They found that PNCs near 
the road were generally higher in open terrain situations with no barriers present, but decreased faster with distance during no barrier situation compared with the cases when vegetation barriers were present. A recent modelling study by Steffens et al. (2012) applied CTAG (Comprehensive Turbulent Aerosol Dynamics and Gas Chemistry) model for studying the effect of vegetation barriers on near-road particles. They compared their modelled results against the field measurements collected by Hagler et al. (2012) and reported that the model over-predicts the PNCs for particles below $50 \mathrm{~nm}$ in diameter, while an adequate agreement was seen for particles greater than $50 \mathrm{~nm}$ in diameter.

Some numerical and physical modelling studies have focused on the effect of different types of vegetation on the PNC removal. For example, Lin and Khlystov (2011) reported removal efficiency of ultrafine particles (particle diameter smaller than $100 \mathrm{~nm}$ ) using pine and juniper branches in a wind tunnel facility. They found removal efficiency of ultrafine particles directly proportional to the packing density, but inversely proportional to particle size and wind speed. Their latter work (Lin et al., 2012) proposed an analytical model based on the measured removal efficiency. Their modelled results of the branches collection efficiency were within $20 \%$ of those measured during wind tunnel measurements for a wind velocity range of $0.3-1.5 \mathrm{~m} \mathrm{~s}^{-1}$. A few studies have also studied the dry deposition velocity at different type of tree leaves. For instance, Petroff et al. (2008) proposed aerosol dry deposition model for vegetation. They concluded that the deposition of particles less than 80 $\mathrm{nm}$ is controlled by Brownian diffusion, while the deposition of larger particles is determined by interception and inertial impaction. Later, Hwang et al. (2011) studied five different types of vegetation in a deposition chamber. They reported higher deposition velocity of submicron (particle diameter $<1 \mu \mathrm{m}$ ) and ultrafine particles for needle leaf trees compared with those for broad leaf trees. They also found that the surface roughness of tree leaves influenced the deposition efficiency strongly.

A limited number of modelling studies have examined the influence of vegetation barriers on the dispersion of traffic-produced $P N C$ in various size ranges, and field investigations on this topic are even rarer (see Table 1). Our study experimentally investigates the effect of vegetation barrier on freshly emitted nanoparticles from the road traffic. The fraction of the inhaled particles deposited in the human respiratory tract (sum of alveolar, tracheobronchial and extrathoracic regions), which are referred to as respiratory deposited doses (RDD; see Section 2.5), is also determined for the three prevalent wind directions observed during the Cite this article as: Al-Dabbous, A.N., Kumar, P., 2014. The influence of roadside vegetation barriers on airborne nanoparticles and pedestrians exposure under varying wind condition. Atmospheric Environment 90, 113-124. Online Link: http://dx.doi.org/10.1016/j.atmosenv.2014.03.040 
experimental campaigns. There are four unique features of this study. Firstly, a fast response differential mobility spectrometer (DMS50), which provided the real-time measurements of particles in the 5-560 $\mathrm{nm}$ size range, is deployed for the measurements. These fast response measurements allowed capture of the rapid transformation of nano-size particles and their concentration peaks that would have been missed if an instrument with a lower sampling rate had been used; see review by Kumar et al. (2010). Secondly, a purposely designed solenoid system was used to measure PNC at four sampling locations pseudo-simultaneously - these locations encompassed through the vegetation barrier and allowed us to make novel comparisons. Thirdly, most of the published work has focused on numerical or physical modelling of particles near the roadside barriers (see Table 1), but our experimental setup allowed capturing of the penetration of particles through the vegetation barrier. Finally, our fast response sequential measurements of the size-resolved PNDs at the sides and in-between the vegetation barrier (see Section 2.1) are among the first field measurements of this kind, representing absolute values of both the PNDs and PNCs. These data can assist in understanding their mitigation potential and facilitate performance evaluation of theoretical models.

Table 1: Summary of the results of numerous modelling and field studies that have studied the influence of vegetation on nanoparticles.

\begin{tabular}{|c|c|c|c|c|}
\hline Author (year) & Site & $\begin{array}{l}\text { Size } \\
\text { range } \\
(\mathrm{nm})\end{array}$ & $\begin{array}{l}\text { Instrum } \\
\text { ent }\end{array}$ & Notes \\
\hline $\begin{array}{l}\text { Brantley et al. } \\
\text { (2014) }\end{array}$ & $\begin{array}{l}\text { Field } \\
\text { measurements }\end{array}$ & $\begin{array}{l}500- \\
10000\end{array}$ & HHPC-6 & $\begin{array}{l}\text { Diurnal changes in wind direction } \\
\text { significantly decreased the pollutant } \\
\text { concentrations behind the tree stands, but } \\
\text { PNC in the } 500-10000 \mathrm{~nm} \text { size range did } \\
\text { not show such reductions. }\end{array}$ \\
\hline $\begin{array}{l}\text { Hagler et al. } \\
\text { (2012) }\end{array}$ & $\begin{array}{l}\text { Field } \\
\text { measurements }\end{array}$ & -- & $\begin{array}{l}\text { EEPS; } \\
\text { CPC; } \\
\text { APS; } \\
\text { FMPS; } \\
\text { SMPS }\end{array}$ & $\begin{array}{l}\text { No reduction in PNCs was observed behind } \\
\text { the noise barrier for the upwind cases, } \\
\text { while a mean reduction of } 47 \% \text { was } \\
\text { observed in other wind directions. Impact } \\
\text { of vegetation barrier on PNCs was } \\
\text { inconclusive due to the variable } \\
\text { meteorological and vegetation conditions. }\end{array}$ \\
\hline $\begin{array}{l}\text { Baldauf et al. } \\
\text { (2008) }\end{array}$ & $\begin{array}{l}\text { Field } \\
\text { measurements }\end{array}$ & -- & $\begin{array}{l}\text { P-Trak; } \\
\text { DMA; } \\
\text { CPC; } \\
\text { SMPS }\end{array}$ & $\begin{array}{l}\text { Solid noise barrier were found to reduce up } \\
\text { to } 50 \% \text { of PNCs. Combination of noise } \\
\text { and vegetation barriers was found to } \\
\text { reduce the PNCs more efficiently than the } \\
\text { noise barrier alone. }\end{array}$ \\
\hline This study & $\begin{array}{l}\text { Field } \\
\text { measurements }\end{array}$ & $5-560$ & DMS50 & $\begin{array}{l}\text { Number and size distributions of particles } \\
\text { at the front, middle and back of a } \\
\text { vegetation barrier assessed. Another } \\
\text { sampling location was at vegetation free } \\
\text { location. PNCs were found to be reduced }\end{array}$ \\
\hline
\end{tabular}

Cite this article as: Al-Dabbous, A.N., Kumar, P., 2014. The influence of roadside vegetation barriers on airborne nanoparticles and pedestrians exposure under varying wind condition. Atmospheric Environment 90, 113-124. Online Link: http://dx.doi.org/10.1016/j.atmosenv.2014.03.040 


\begin{tabular}{|c|c|c|c|c|}
\hline & & & & $\begin{array}{l}\text { by } 37 \% \text { due to the presence of vegetation } \\
\text { barrier. }\end{array}$ \\
\hline $\begin{array}{l}\text { Steffens et al. } \\
(2012)\end{array}$ & Modelling & $12.6-289$ & $\begin{array}{l}\text { SMPS; } \\
\text { FMPS }\end{array}$ & $\begin{array}{l}\text { The sensitivity analysis revealed nonlinear } \\
\text { increase in deposition based on large leaf } \\
\text { area density. } \\
\text { Increase in wind speed, reduce particle } \\
\text { diffusion, reduce particle concentration for } \\
D_{p}>50 \mathrm{~nm} \text { but have least effects for } D_{p} \\
<50 \mathrm{~nm} \text {. }\end{array}$ \\
\hline $\begin{array}{l}\text { Petroff et al. } \\
(2008)\end{array}$ & Modelling & -- & -- & $\begin{array}{l}\text { The development of the model was based } \\
\text { on aerosol interaction with vegetation } \\
\text { canopy. Despite ignoring physical and } \\
\text { chemical interaction of aerosol chemistry, } \\
\text { the model has resoled aerosol interaction } \\
\text { with terrestrial vegetation. }\end{array}$ \\
\hline $\begin{array}{l}\text { Bowker et al. } \\
\text { (2007) }\end{array}$ & Modelling & $20-75$ & $\begin{array}{l}\text { DMA; } \\
\text { CPC }\end{array}$ & $\begin{array}{l}\text { QUIC model was applied and compared } \\
\text { with the ultrafine particles mobile } \\
\text { measurements for all experimental } \\
\text { conditions studied. }\end{array}$ \\
\hline $\begin{array}{l}\text { Lin et al. } \\
(2012)\end{array}$ & Wind tunnel & $12.6-102$ & SMPS & $\begin{array}{l}\text { An analytical model was developed for } \\
\text { collection efficiency at tree branches for } \\
\text { particles less than } 100 \mathrm{~nm} \text { in diameter. The } \\
\text { vegetation drag coefficient is not affected } \\
\text { by branch orientation. Brownian diffusion } \\
\text { is the major contributor for collection } \\
\text { efficiency. }\end{array}$ \\
\hline $\begin{array}{l}\text { Lin and } \\
\text { Khlystov } \\
(2011)\end{array}$ & Wind tunnel & $12.6-102$ & SMPS & $\begin{array}{l}\text { The filtration theory is the correct } \\
\text { mechanism for removal of particles }<100 \\
\mathrm{~nm} \text {. }\end{array}$ \\
\hline $\begin{array}{l}\text { Hwang et al. } \\
\text { (2011) }\end{array}$ & Chamber & $300-600$ & $\begin{array}{l}\text { DMA; } \\
\text { CPC }\end{array}$ & $\begin{array}{l}\text { Deposition of particles are function of } \\
\text { surface roughness of tree leaves (the } \\
\text { courser the leaves, higher the removal of } \\
\text { particles). }\end{array}$ \\
\hline
\end{tabular}

Note: DMA $=$ Differential Mobility Analyser; $\mathrm{CPC}=$ Condensation Particle Counter; EEPS $=$ Engine Exhaust Particle Sizer; APS = Aerosol Particle Sizer; FMPS = Fast Mobility Particle Sizer; SMPS = Scanning Mobility Particle Sizer; HHPC-6 = Hand-held particle counter; DMS50= differential mobility spectrometer

\section{DATA COLLECTION}

\subsection{Site description}

Figure 1 presents the detailed schematic diagram of the sampling site. The monitoring was carried out adjacent to the A3 road in Guildford, UK $\left(+51^{\circ} 14^{\prime} 37.08 " \mathrm{~N},+0^{\circ} 35^{\prime}\right.$ $47.00 " \mathrm{~W})$. This road runs approximately north to south (N-S), connecting Guildford town to London and the south-coast. It has four traffic lanes and the width of the each lane is $\sim 3.20$ m. Two lanes carry the traffic in each direction. There were no exhaust or non-exhaust sources (e.g. power plant emissions, wood burning) in the close vicinity of the measurement 
site. Given that the measurements were taken within few meters of the roadside (see Figure 1), road traffic is the main source of nanoparticles at the sampling site. The average traffic volume during the measurement periods varied between 6000 and $6600 \mathrm{veh} \mathrm{h}^{-1}$. Cars dominated the traffic fleet since these had $\sim 97 \%$ share of the total traffic volume. Further details of the daily traffic statistics can be seen in Table 2 .

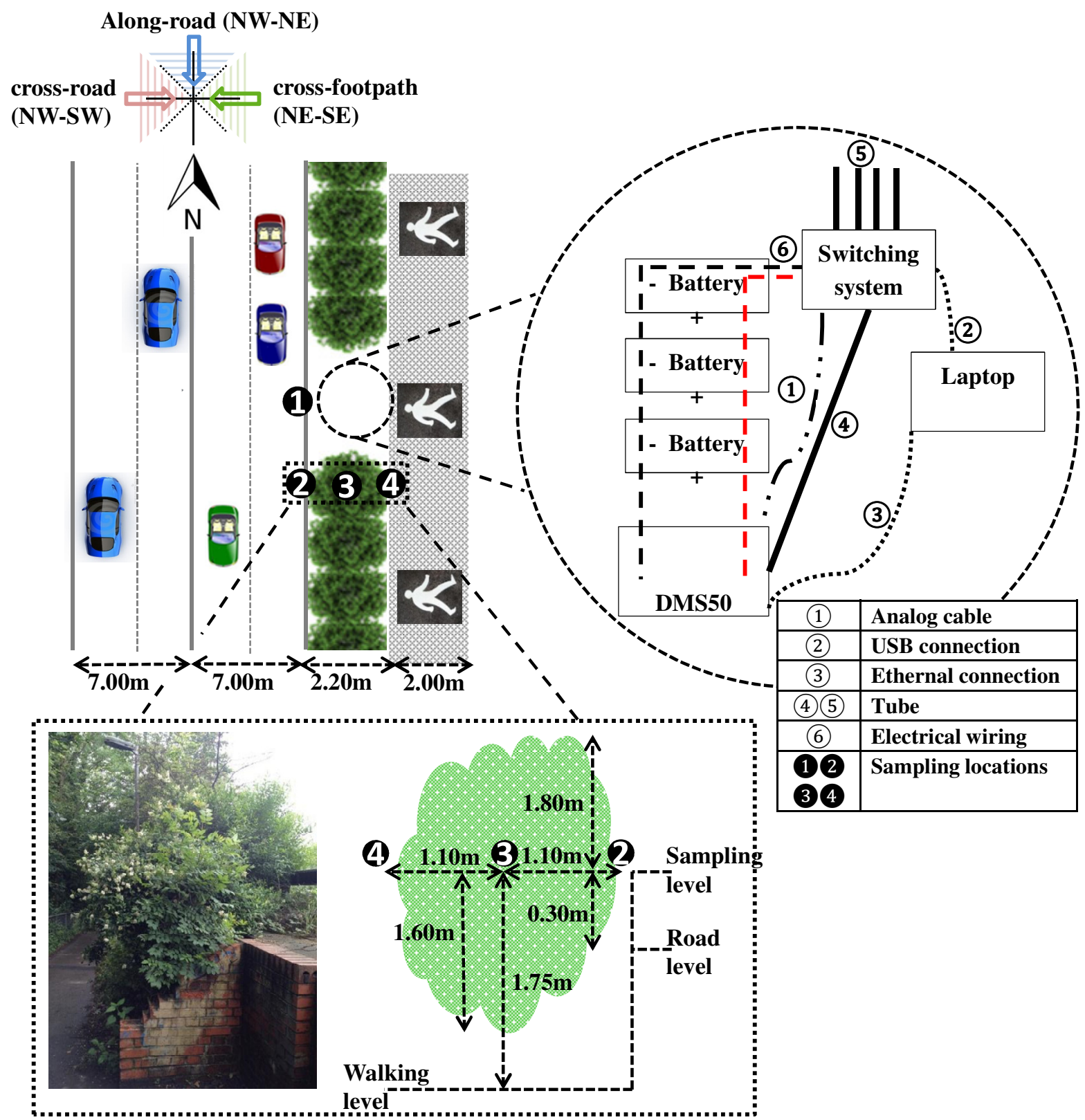

Figure 1: Schematic diagram of the sampling site showing the sampling locations and experiment setup as described in the text. Please note that the figure is not to scale. The arrows for different wind directions (NW-NE; NW-SW; NE-SE) indicate the direction of the blowing of the wind. 
The exact location of the experimental site is at the west end of the University of Surrey behind the Guildford School of Acting, as shown in Supplementary Information (SI) Figure S1. Guildford town is considered as one of the most populated areas in Guildford Borough, which is part of Surrey County Council. Current population of the Guildford Borough is 137,183, which represent $~ 12 \%$ of Surrey County population (Surrey-i, 2012). About $72 \%$ of Surrey residents rely on cars for transport to work, and $\sim 42 \%$ trips to schools are by cars compared with only $36 \%$ and $31 \%$ in the South East England and nationally in the UK, respectively (Guildford-Borough, 2009).

Table 2: Total traffic volume (veh $\mathrm{hr}^{-1}$ ) during the sampling period explained in Table 3 . WB and $\mathrm{EB}$ refer to west-bound and east-bound directions of road traffic, respectively. The sum of WB and EB gives the total hourly traffic on both the lanes of road.

\begin{tabular}{llllllll}
\hline \multirow{2}{*}{$\begin{array}{l}\text { Day } \\
\text { No. }\end{array}$} & \multicolumn{2}{l}{ Motorcycles } & Cars & \multicolumn{3}{c}{ Trucks } & Total \\
\cline { 2 - 6 } & WB & EB & WB & EB & WB & EB & \\
\hline D1 & 88 & 23 & 3206 & 3256 & 16 & 26 & 6615 \\
D2 & 11 & 20 & 3267 & 2711 & 14 & 19 & 6042 \\
D3 & 35 & 21 & 3580 & 2848 & 31 & 41 & 6556 \\
D4 & 63 & 20 & 3269 & 2813 & 20 & 23 & 6209 \\
D5 & 54 & 19 & 3251 & 3246 & 35 & 33 & 6638 \\
D6 & -- & -- & -- & -- & -- & -- & -- \\
\hline
\end{tabular}

As seen in Figure 1, there is a $2.20 \mathrm{~m}$ wide vegetation barrier on the east side of the road that is situated at a distance of $\sim 0.30 \mathrm{~m}$ from the road. This vegetation barrier consists of many convergent trees situated in one straight line. The studied section of the vegetation barrier is made of coniferous plants. The vegetation during the monitoring campaigns had densely foliated tree line and the openings were only provided by the space between the tree leaves and the branches. The full height of barrier between the crown and the bottom stem near the ground level is covered by the green leaves. The vegetation barrier height at the studied section was $3.40 \mathrm{~m}$ above the ground level. The sampling height was around $1.60 \mathrm{~m}$ above the ground level and $0.30 \mathrm{~m}$ above the street level (see figure 1). The vegetation barrier was continuous along the roadway from the south and north sides of the sampling site. The unique layout of the vegetation barrier provided the opportunity to compare the concentrations of nanoparticles near the road, with and without the vegetation, as well as the nanoparticles variation through the vegetation barrier (see sampling locations in Figure 1). A busy footpath runs parallel to the vegetation barrier, which has a width of $\sim 2 \mathrm{~m}$ and is located $1.45 \mathrm{~m}$ below the road level.

Cite this article as: Al-Dabbous, A.N., Kumar, P., 2014. The influence of roadside vegetation barriers on airborne nanoparticles and pedestrians exposure under varying wind condition. Atmospheric Environment 90 , 


\subsection{Instrumentation}

The experimental setup is comprised of a DMS50 and a fully automated solenoid switching system - both these were connected to three $12 \mathrm{~V}$ leisure batteries and laptop (see Figure 1). The DMS50 is essentially the same as its parent version, DMS500 (Kumar et al., 2008a), but has a unique capability to run on batteries making it suitable for portable measurements where power supply is unavailable. The DMS50 measures size-resolved particles in the 5-560 $\mathrm{nm}$ size range through the 34 size bins. The instrument is capable to collect data at a $10 \mathrm{~Hz}$ sampling rate, with time response ( $\mathrm{T}_{10-90 \%}$ as 500 milliseconds). Another essential feature of the DMS50 is its ability to work at close to atmospheric pressure and eliminate the use of an external vacuum pump. The DMS50 works on electrical mobility detection technique to classify the particles in various size ranges. As air is drawn from the ambient environment by the suction pump of the DMS50 and exposed to unipolar diffusion charger, a positive charge is placed on each particle, depending on their surface area. These positively charged particles then lands on electrometer detectors, depending on their charge, and thus the particle number and size distributions are calculated according to measured charge on each particle (see details in Kumar et al., 2010). The DMS50 has been successfully deployed in a broad variety of our previous work, involving indoor measurements (Kumar et al., 2012), outdoor measurements in vehicle wakes (Carpentieri and Kumar, 2011) and car cabin measurements (Joodatnia et al., 2013a, b).

A short length $(0.50 \mathrm{~m})$ of conductive silicone tube was used to connect the DMS50 with the switching system. The similar types of $3.50 \mathrm{~m}$ long tubes were connected to the 4-way solenoid switching system to reach to the four designated sampling locations (Figure 1). The switching system is capable of automatically switching the sample flow between a maximum of four measurement points, providing pseudo-simultaneous measurements, with selectable switching times. This DC-powered solenoid switching system was firstly designed and used by Kumar et al. (2008b). This system was recently modified to make it fully automatic and controllable by the computer before using in our recent studies (Joodatnia et al., 2013a, b). A Panasonic HC-V500 video camera was used to collect traffic data in order to correlate the traffic density with the PNCs during the sampling periods. These videos were analysed manually to count the traffic volume into three different categories (i.e. motorcycles, cars and trucks) since buses were found to be negligible. During the measurement period, meteorological data (i.e. temperature, relative humidity, wind speed and direction) was 
collected from the UK Met Office weather station located at Royal Horticultural Society's garden in Wisley, Surrey ( 10 km to the North-East of Guildford) at an altitude of $36 \mathrm{~m}$ above the mean see level. The weather station is located in the rural area of Wisley, surrounded by a large area of orchards in the close vicinity and agricultural lands in the far vicinity. The location of this weather station keeps the measurements free from the local ground-level turbulence. This is run by the UK Met Office, which maintains the quality control of the collected data that have also been used by other studies (e.g. Burt and Eden, 2004). During the measurement campaigns, the wind speed varied between 1.5 and $3.60 \mathrm{~m} \mathrm{~s}^{-}$ ${ }^{1}$. The temperature and the relative humidity ranged the $2-23{ }^{\circ} \mathrm{C}$ and $45-85 \%$, respectively. Detailed summary of meteorological conditions during the experimental campaigns is provided in Table 3.

Table 3: Sampling dates, times and meteorological conditions during the sampling periods.

\begin{tabular}{lllllll}
\hline $\begin{array}{l}\text { Day } \\
\text { number }\end{array}$ & Date & Time & $\begin{array}{l}\text { Mean } \\
\text { wind } \\
\text { speed } \\
\left(\mathrm{m} \mathrm{s}^{-1}\right)\end{array}$ & $\begin{array}{l}\text { Wind } \\
\text { direction } \\
\left({ }^{\circ}\right)\end{array}$ & $\begin{array}{l}\text { Mean } \\
\text { temperature } \\
\left({ }^{\circ} \mathrm{C}\right)\end{array}$ & $\begin{array}{l}\text { Mean } \\
\text { relative } \\
\text { humidity } \\
(\%)\end{array}$ \\
\hline D1 & $07 / 08 / 2012$ & $16: 23-18: 33$ & 2.57 & $230-250$ & 16 & 84.5 \\
D2 & $11 / 08 / 2012$ & $12: 59-14: 44$ & 3.08 & $100-120$ & 23.3 & 44.6 \\
D3 & $21 / 02 / 2013$ & $14: 09-15: 20$ & 2.92 & $80-90$ & 2.1 & 51.7 \\
D4 & $24 / 02 / 2013$ & $14: 58-16: 48$ & 3.60 & 360 & 1.9 & 71.5 \\
D5 & $27 / 02 / 2013$ & $14: 23-16: 27$ & 3.43 & $30-40$ & 4.9 & 72.3 \\
D6 & $03 / 03 / 2013$ & $15: 03-17: 00$ & 1.54 & $110-120$ & 6.9 & 70 \\
\hline
\end{tabular}

\subsection{Data acquisition}

For the quality assurance, the DMS50 was calibrated by the manufacturer in January 2013 and was within the one year calibration period during the measurements. The DMS50 was cleaned manually from the inside and tested in the laboratory before each sampling day for proper operation and data collection. Air samples were collected at $1 \mathrm{~s}$ sampling rate (i.e. average of 10 samples) in order to improve the signal-to-noise ratio for attaining high quality data (Kumar et al., 2009). Sequential measurements for $20 \mathrm{~s}$ are taken at each sampling point by auto-redirecting the sampling flow between four sampling locations $\left(L_{1}-L_{4}\right)$. One full cycle of measurements, covering all the four points $\left(L_{1}-L_{4}\right)$, took a total of $80 \mathrm{~s}$. Therefore, one hour of monitoring completed 45 full cycles and $900 \mathrm{~s}$ of sampling was done at each of the sampling locations during each hour. The system is designed in such a way that the lag time between the switching is modest since the sample air is sucked at all times from all the four sampling locations, but this only channelize the sample air from one of the locations to the

Cite this article as: Al-Dabbous, A.N., Kumar, P., 2014. The influence of roadside vegetation barriers on airborne nanoparticles and pedestrians exposure under varying wind condition. Atmospheric Environment 90, 113-124. Online Link: $\quad$ http://dx.doi.org/10.1016/j.atmosenv.2014.03.040 
instrument. For avoiding any switching artefacts and maintaining the quality control, only 16 $\mathrm{s}$ of data after discarding the first $2 \mathrm{~s}$ and the last $2 \mathrm{~s}$ of measurement data from each sampling location during every cycle were used for analysis. Further details of the sampling dates and times can be seen in Table 3. Estimations based on the instrument flow rate $(6.5 \mathrm{slpm})$ and the dimension of the tube (length $3.5 \mathrm{~m}$, and internal diameter $0.005 \mathrm{~m}$ ) gives a lag time of about $0.6 \mathrm{~s}$ between the inlets of the sampling tube and the DMS50. The lag time is trivial given that we have already disregarded $\sim 4 \mathrm{~s}$ of data from the measurements taken at each location during every cycle. DMS50 and switching system were operated by three $12 \mathrm{~V}$ leisure batteries, which were charged in the laboratory before each sampling day.

As seen in Figure 1, sampling locations $L_{2}, L_{3}$ and $L_{4}$ were situated at front $\left(L_{2}\right)$, middle $\left(L_{3}\right)$ and back $\left(L_{4}\right)$ of the vegetation barrier in a line perpendicular to the road. $L_{2}$ was $\sim 0.30 \mathrm{~m}$ away from the edge of the road; $L_{3}$ and $L_{4}$ were $1.1 \mathrm{~m}$ and $2.2 \mathrm{~m}$ away from the $L_{2}$, respectively. Sampling location, $L_{1}$, was purposely chosen at the same distance from the road in parallel with the $L_{2}$ in order to evaluate the effect of vegetation barrier on the particles in various size ranges during cross-road wind conditions (see Figure 1). All the sampling locations were placed at the same vertical height (i.e. $0.30 \mathrm{~m}$ ) from the road surface and $\sim 1.75 \mathrm{~m}$ above the footpath level, representing the typical breathing height of the public using the footpath.

In order to study the influence of wind directions, which is important to understand whether the wind flow is across or along the vegetation barrier and the corresponding advection (i.e. the transport of particles by wind), the total data collected over the sampling duration were divided into the three available wind conditions (see Figure 1). There were no prevailing winds observed from SE-SW during the study period and therefore are not mentioned hereafter in the discussions. These included: (i) NW-SW, which represent the wind blowing from the A3 road towards the sampling location after passing through the road and vegetation barrier (hereafter referred as cross-road winds), (ii) NE-SE, which represents the wind blowing from the sampling location towards the A3 road after passing through the footpath and then the vegetation barrier (cross-footpath winds), and (iii) NW-NE, which represents the wind blowing parallel to the A3 road (along-road winds).

Visual Basic code was developed in the Microsoft Office Excel to sort the size resolved PNC and PND data at each of the four locations. These data were then analysed by Microsoft Cite this article as: Al-Dabbous, A.N., Kumar, P., 2014. The influence of roadside vegetation barriers on airborne nanoparticles and pedestrians exposure under varying wind condition. Atmospheric Environment 90, 113-124. Online Link: $\quad$ http://dx.doi.org/10.1016/j.atmosenv.2014.03.040 
Office Excel with the use of a DMS50 data processing tool. A total of more than 37,300 valid samples of size resolved particle number and size distributions were recorded intermittently (see Table 3). The reason for choosing these intermittent short measurement periods were the lack of secured place and power supply for unattended continuous operation.

\subsection{Particles losses in the sampling tube}

Losses of particles in long sampling tube due to their diffusion is an important issue, particularly for particles less than $20 \mathrm{~nm}$, and should be taken into consideration for sampling tubes greater than one meter (Kumar et al., 2008c). In order to maintain the similar effect on the measured size distributions, identical length (i.e. $3.5 \mathrm{~m}$ ) of conductive sampling tubes, made of silicone, were used to collect samples from all the four sampling locations. The particle losses in sampling tubes is likely to affect the absolute values of measured concentrations, either by underestimating them or overestimating the geometric mean diameter, GMD (Carpentieri and Kumar, 2011). The GMD provides typical average diameter of size distributions. Relative changes in GMD help in assessing the influence of transformation process (e.g. nucleation, coagulation) and deposition on tree leaves (see Section 3.2.1). Therefore, we corrected our measured data for particles losses in the sampling tube following the approach described in Kumar et al. (2008c). A comparison between the measured and corrected PNCs is tabulated in SI Table S1 to demonstrate the differences due to particle losses. Corrected values of particle number and size distributions are used in our subsequent analysis.

\subsection{Estimation of particle respiratory deposited doses in human respiratory tract}

Inhaled particle deposition depend on the following key physiological factors: the tidal volume $\left(\mathrm{V}_{\mathrm{T}}\right)$, and the breathing frequency $(f)$ (Hofmann, 2011). The product of these two factors $\left(\mathrm{V}_{\mathrm{T}} \times f\right)$ gives the minute ventilation (VE), which depends on the physical activity (Hofmann, 2011; ICRP, 1994). The inhaled amount of particles was computed by multiplying the concentration (i.e. total PNC) with the VE. Finally, the fraction of the inhaled particles, which is estimated to remain in the human respiratory tract for every minute (i.e. respiratory deposited dose, RDD), was calculated by multiplying the inhaled amount with the corresponding deposition fraction (DF). The same approach was used by other recent exposure assessment studies (Int Panis et al., 2010; Joodatnia et al., 2013a).

Cite this article as: Al-Dabbous, A.N., Kumar, P., 2014. The influence of roadside vegetation barriers on airborne nanoparticles and pedestrians exposure under varying wind condition. Atmospheric Environment 90, 113-124. Online Link: $\quad$ http://dx.doi.org/10.1016/j.atmosenv.2014.03.040 
For computing the RDD, the values of a VE are chosen as $2.5 \times 10^{4} \mathrm{~cm}^{3} \min ^{-1}\left(\mathrm{~V}_{\mathrm{T}}=1.25 \mathrm{~L}\right.$ and $f=20$ breaths $\left.\min ^{-1}\right)$ and $2.08 \times 10^{4} \mathrm{~cm}^{3} \min ^{-1}\left(\mathrm{~V}_{\mathrm{T}}=0.99 \mathrm{~L}\right.$ and $f=21$ breaths $\left.\mathrm{min}^{-1}\right)$ for adult male and female subjects with light level of exercise, respectively (Hinds, 1999).

The DF can be taken as a fixed value based on the GMD of the total PNCs, or based on the detailed particle size distributions (Joodatnia et al., 2013a). Here, we have used both the fixed and size-dependent DF for calculating the RDD during different wind directions (see SI Section S1). Fixed values of DFs were calculated for each sampling location, based on the associated GMD of the measured PNDs during each wind direction, as shown in Table S2. Their average values were estimated as 0.70 for cross-road, 0.80 for cross-footpath, and 0.83 for along-road winds. These values were in the range of those available in previously published studies. For instance, Daigle et al. (2003) reported a DF of 0.83 for males with light exercise. Following the International Commission on Radiological Protection model (ICRP, 1994), size-dependent DFs for each of the 32 size bins are also calculated (see Figure S2), and these DFs are used for the estimation of size-dependent RDD.

\section{RESULTS AND DISCUSSION}

For investigating the behaviour of particles in different size ranges, the PNC data are divided into four size ranges: 5-30 $\mathrm{nm}\left(\mathrm{N}_{5-30}\right.$; nucleation mode), 30-100 nm $\left(\mathrm{N}_{30-100}\right.$; Aitken mode), 100-300 nm ( $\mathrm{N}_{100-300}$; accumulation mode) and 300-560 nm ( $\mathrm{N}_{300-560}$; coarse mode). The measured data has been discussed into two segments. Discussions are firstly made on the characteristics of nanoparticles close to the road by selecting the sampling location adjacent to the roadside with $\left(L_{2}\right)$ and without $\left(L_{1}\right)$ the vegetation barrier. The remaining sampling locations $\left(L_{2}-L_{4}\right)$ are then chosen to analyse the particle removal by the vegetation barrier.

The background PNCs were measured at an open grassy field at the side of the University of Surrey's campus. The field was $\sim 300 \mathrm{~m}$ away on the east side of the sampling site and the measured background PNCs were noted as $1.31 \pm 0.57 \times 10^{4} \mathrm{~cm}^{-3}$ (see Table S3 for details).

\subsection{Characteristics of nanoparticles close to the road}

\subsubsection{PNDs close to the road}

In order to assess the PNDs close to the road, location $L_{1}$ is selected for discussion. Irrespective of wind direction, PNDs showed consistent high peaks in nucleation mode range but their magnitude changed for different directions (see Figure 2). For all the wind Cite this article as: Al-Dabbous, A.N., Kumar, P., 2014. The influence of roadside vegetation barriers on airborne nanoparticles and pedestrians exposure under varying wind condition. Atmospheric Environment 90, 113-124. Online Link: $\quad$ http://dx.doi.org/10.1016/j.atmosenv.2014.03.040 
directions, the highest peak was observed at $5.6 \mathrm{~nm}$, followed by $10 \mathrm{~nm}$ and a varying peak between 55 and $75 \mathrm{~nm}$. The PND peaks at 5.6 and $10 \mathrm{~nm}$ were highest during the along-road winds (Figure 2c), presumably due to the sweeping of on-road emissions towards the sampling location by the wake of vehicles (Carpentieri and Kumar, 2011). The second highest peaks corresponding to 5.6 and $10 \mathrm{~nm}$ were observed during the cross-road winds (Figure 2a) - these may have arisen due to the transport of vehicle emissions by the wind towards the sampling location $\left(L_{1}\right)$. The lowest values of the peak PNDs were observed at 5.6 and $10 \mathrm{~nm}$ during the cross-footpath winds. These were expected due to the fact that winds were likely to carry the particles away from the sampling location. The third peak was noticed to be variable, which changed between 55 and $75 \mathrm{~nm}$, during the three wind directions. These peaks were observed at $\sim 55,65$ and $75 \mathrm{~nm}$ diameter during the crossfootpath, along-road and cross-road winds, respectively. Given that the particles in the accumulation mode do not behave in a similar manner to those in nucleation mode under identical wind conditions and a much better correlation of them with the wind speed is observed by previous field studies (e.g., Kumar et al., 2008a), these variations could be attributed to the differences in extent of advection experienced by the sampling location during the three wind directions (see Section 3.2.1).

Cite this article as: Al-Dabbous, A.N., Kumar, P., 2014. The influence of roadside vegetation barriers on airborne nanoparticles and pedestrians exposure under varying wind condition. Atmospheric Environment 90, 113-124. Online Link: http://dx.doi.org/10.1016/j.atmosenv.2014.03.040 

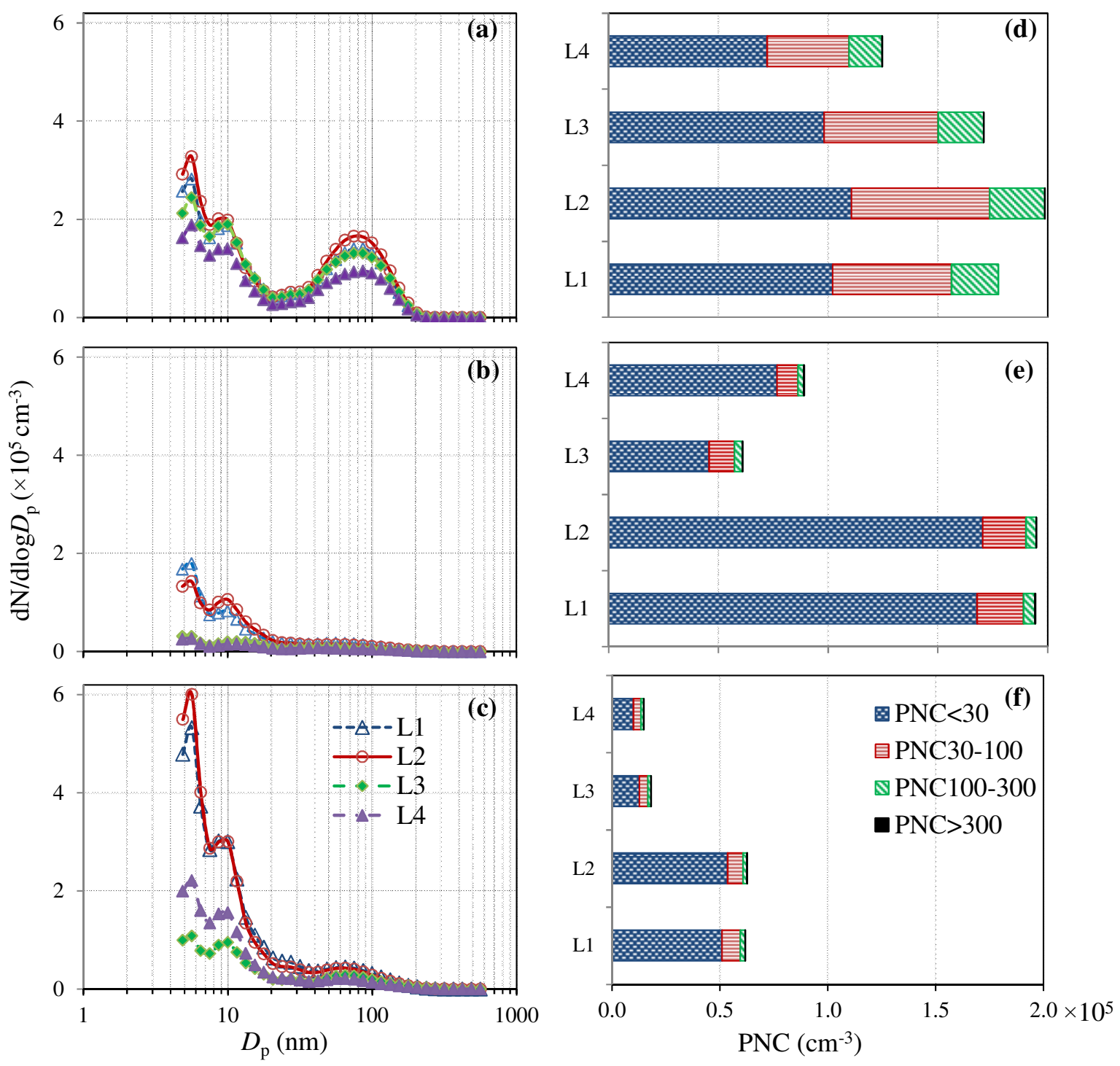

Figure 2: Particle size distribution and concentrations in four different size ranges at various sampling locations during (a, d) cross-road, (b, e) cross-footpath, and (c, f) along-road winds.

The above observations corroborate well with the past roadside studies of nanoparticles, which have exhibited similar peaks. For instance, Lingard et al. (2006) measured trafficderived particles in the 6-10,000 $\mathrm{nm}$ size range at an urban roadside location in Leeds, UK, covering morning, afternoon and evening rush hours. They observed peaks at $\sim 8,12,40,136$ nm during afternoon/evening which are somewhat comparable to those observed in our study. Likewise, Zhu et al. (2002b) previously reported three modes in measured PNDs with peaks at 12.6, 27.3 and $65.3 \mathrm{~nm}$ during their measurements of PNCs near to a major highway in Los Angeles, USA. Their traffic fleet contained less than 5\% diesel vehicles, which are somewhat similar to what we estimated in our study (see Table 2). The appearance of two fresh nucleation mode peaks at 5.6 and $10 \mathrm{~nm}$ in the present study, compared with $12.6 \mathrm{~nm}$ in Cite this article as: Al-Dabbous, A.N., Kumar, P., 2014. The influence of roadside vegetation barriers on airborne nanoparticles and pedestrians exposure under varying wind condition. Atmospheric Environment 90, 113-124. Online Link: http://dx.doi.org/10.1016/j.atmosenv.2014.03.040 
Zhu et al. (2002b), can be related to the distance of the sampling locations from the road. Our measurement location was very close $(\sim 0.30 \mathrm{~m})$ to the road, compared with $\sim 30 \mathrm{~m}$ in the study of Zhu et al. (2002b), allowing us to measure much fresher nucleation mode particles.

\subsubsection{Total PNCs and their fraction in various size ranges close to the road}

Table 4 shows the total, maximum and minimum PNCs and the GMD observed at the sampling locations $L_{1}-L_{4}$ during the three prevalent wind conditions. For the purpose of assessing the PNC close to the roadside, we have picked up the location $L_{1}$ for discussions that has no vegetation barrier on its back-side (see Figure 1). For this reason, particles were passed freely without the vegetation obstruction through the inlet of the DMS50 in high concentrations. The standard deviations for the total PNCs were also found to be large because of varying traffic flow and volume (Table 4).

The sampling location $L_{1}$ is close to the edge of the road and is considered to be within the wake region of the passing road vehicles (Carpentieri and Kumar, 2011). The prevailing mechanism for mixing and dilution of the PNCs is mainly due to the two types of turbulences - traffic-produced (TPT) and wind-produced (WPT) - and the advection effects brought by the resulting wind speed (i.e. net sum of wind and wake speed from the traffic) during the three wind directions. Given the fact that the measurements were in the close proximity to the road and traffic speed on highways is expected to be much higher than the wind speed, the TPT is likely to play a dominant role in influencing the measurements close to the roadsides (Kumar et al., 2008a; Venkatram et al., 2007). The effect of TPT is believed to be minimal during cross-footpath winds compared to cross-road and along-road winds, as the wind is likely to shift the vehicle wake away from the sampling location. The effects of the WPT and TPT are likely to have added effects on sampling locations during cross-road and along-road winds as opposed to cross-footpath winds. The net effect of turbulence and the resulting wind speed at each sampling location can therefore explain the concentration differences obtained during the three wind directions. Among the three wind directions studied, the total PNCs were found to be the highest for along-road winds $\left(1.94 \pm 0.25 \times 10^{5} \mathrm{~cm}^{-3}\right)$, followed by the cross-road $\left(1.78 \pm 1.64 \times 10^{5} \mathrm{~cm}^{-3}\right)$ and cross-footpath $\left(6.17 \pm 2.58 \times 10^{4} \mathrm{~cm}^{-3}\right)$ winds. During the cross-footpath winds, the wind carries the nanoparticles away from the sampling location, resulting into the lowest PNCs. On the contrary, during the cross-road and along-road winds,

Cite this article as: Al-Dabbous, A.N., Kumar, P., 2014. The influence of roadside vegetation barriers on airborne nanoparticles and pedestrians exposure under varying wind condition. Atmospheric Environment 90, 113-124. Online Link: $\underline{\text { http://dx.doi.org/10.1016/j.atmosenv.2014.03.040 }}$ 
the added effect of resulting wind speed appears to have been responsible for the relatively larger PNCs (Figure 2).

Table 4: Summary of average PNC and GMD at various sampling locations during different wind directions; the " \pm "sign shows the standard deviation values.

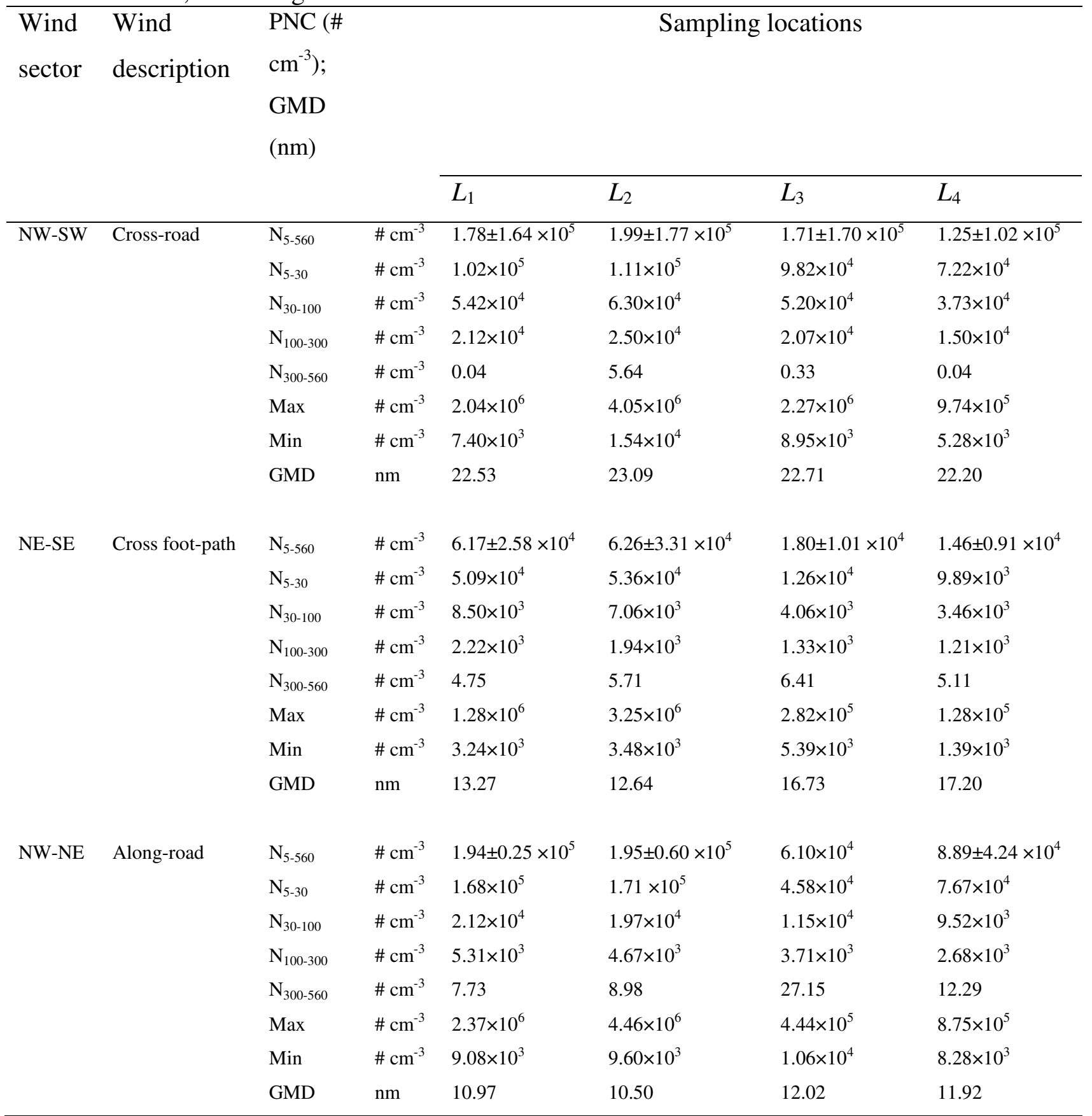

Our PNC values along the roadside for all the wind directions are up to 4-times higher than those reported by Morawska et al. (2008). They reported average PNCs as $\sim 4.81 \pm 4.68 \times 10^{4}$ $\mathrm{cm}^{-3}$ for 18 roadside measurements in various locations around Europe, America and Australia. However, a direct comparison with our results is not possible given the varying

Cite this article as: Al-Dabbous, A.N., Kumar, P., 2014. The influence of roadside vegetation barriers on airborne nanoparticles and pedestrians exposure under varying wind condition. Atmospheric Environment 90, 113-124. 
traffic and wind conditions at each site. Therefore the PNCs $\left(1.78 \pm 1.64 \times 10^{5} \mathrm{~cm}^{-3}\right)$ during the cross-road winds was normalised after dividing the total PNC values by the traffic count in order to remove the dependence of PNCs on the traffic volume. We also selected studies that have similar sampling distance from the road (i.e. $0.30 \mathrm{~m}$ ) for comparison purposes. Summary of the results of all these studies is presented in Table 5. As an example, Agus et al. (2007) measured the PNCs at a distance of $0.30 \mathrm{~m}$ from the edge of Narborough road in Leicester (UK). Their traffic-normalised PNCs were found to be 2 2-2-times higher than those measured in our study. The reason for these differences could be attributed to the differences in meteorological conditions and the architectural layout of roughness elements around the site. For instance, Narborough road is aligned by buildings in both sides reflecting a canyonlike layout while the measurements made in our case were on open roadsides. Since the similar roadside studies for open roadsides do not directly provide the measurements close to the road, we have therefore projected the PNCs at identical downwind distance (i.e. $0.30 \mathrm{~m}$ ) from the road using their PNC decay profiles (see Table 5). The comparison suggest that the normalised PNCs in the present study is $\sim 1.5$-fold higher than those reported by Zhu et al. (2002a). On the other hand, our traffic-normalised PNCs were 3.6-fold lower than those reported by Fujitani et al. (2012). The wind speed were lower $\left(\sim 1 \mathrm{~m} \mathrm{~s}^{-1}\right)$ in the field campaigns of Fujitani et al. (2012) than those measured during our study $\left(2.57 \mathrm{~m} \mathrm{~s}^{-1}\right)$. The larger PNC are expected during the low wind speeds due to their limited dispersion (Kumar et al., 2008a). Their higher PNCs can presumably be due to the lower ambient temperature in their study $-6.6{ }^{\circ} \mathrm{C}$ compared with our $16{ }^{\circ} \mathrm{C}$ - as the low temperature tend to favour formation of nucleation mode particles and thereby increasing the total PNCs (Kittelson et al., 2001).

At sampling locations $L_{1}, \mathrm{~N}_{5-30}$ dominates the total PNCs which were found as $\sim 57 \%, 82 \%$ and $86 \%$ during cross-road, cross-footpath and along-road winds, respectively. During crossroad winds, $\mathrm{N}_{30-100}$ and $\mathrm{N}_{100-300}$ were $\sim 31 \%$ and $12 \%$ of the total PNCs, respectively. $\mathrm{N}_{30-100}$ and $\mathrm{N}_{100-300}$ contributed only $\sim 14 \%, 4 \%$ and $11 \%, 3 \%$ of the total PNCs during cross-footpath and along-road winds, respectively. Thus, negligible PNCs were observed for particles greater than $300 \mathrm{~nm}$. The ultrafine particles dominate the total PNCs during all the wind directions; 88, 96 and 97\% for cross-road, cross-footpath and along-road winds, respectively. $\mathrm{N}_{5-30}$ represents the majority of the ultrafine particles with a share of $\sim 65,86$ and $89 \%$ for cross-road, cross-footpath and along-road winds, respectively. These fractions of PNCs

Cite this article as: Al-Dabbous, A.N., Kumar, P., 2014. The influence of roadside vegetation barriers on airborne nanoparticles and pedestrians exposure under varying wind condition. Atmospheric Environment 90, 113-124. Online Link: $\underline{\text { http://dx.doi.org/10.1016/j.atmosenv.2014.03.040 }}$ 
observed at $L_{1}$, which represents vegetation-free measurements, agree well with the literature that shows $\sim 70 \%$ of the PNCs in the ultrafine particles size range (Zhu et al., 2002a).

Table 5: Summary of nanoparticles highway studies, where PNCs are projected at $0.30 \mathrm{~m}$ from the highway. ' $\mathrm{X}$ ' refers to distance $(\mathrm{m})$ from the road.

\begin{tabular}{|c|c|c|c|c|c|c|}
\hline Location & $\begin{array}{l}\text { Size } \\
\text { range } \\
(\mathrm{nm})\end{array}$ & $\begin{array}{l}\text { Traffic } \\
\text { Density } \\
\left(\mathrm{hr}^{-1}\right)\end{array}$ & $\begin{array}{l}\text { PNC decay equations; } \\
\text { total PNC }\left(\# \mathrm{~cm}^{-3}\right)\end{array}$ & $\begin{array}{l}\text { Projected } \\
\text { PNCs at } \\
0.30 \mathrm{~m} \\
\left(\times 10^{5} \mathrm{~cm}^{-}\right. \\
\left.{ }^{3}\right)\end{array}$ & $\begin{array}{l}\text { Normali } \\
\text { sed } \\
\mathrm{PNCs}^{\mathrm{a}}\end{array}$ & Reference \\
\hline $\begin{array}{l}\text { Cassino, } \\
\text { Italy }\end{array}$ & $\begin{array}{l}5.9- \\
20,000\end{array}$ & 5,700 & $7.78 \times 10^{3}+2.51 \times 10^{5} \mathrm{e}^{-0.011 \mathrm{X}}$ & 2.58 & 45.25 & $\begin{array}{l}\text { Buonanno } \\
\text { et al. } \\
\text { (2009) }\end{array}$ \\
\hline $\begin{array}{l}\text { Kawasaki, } \\
\text { Japan }\end{array}$ & $10-1,000$ & 3,100 & $\begin{array}{l}\text { Summer: } 1.07 \times 10^{5} \times \mathrm{X}^{-0.189} \\
\text { Winter: } 2.02 \times 10^{5} \times \mathrm{X}^{-0.337}\end{array}$ & $\begin{array}{l}1.34 \\
3.03\end{array}$ & $\begin{array}{l}43.34 \\
97.77\end{array}$ & $\begin{array}{l}\text { Fujitani et } \\
\text { al. (2012) }\end{array}$ \\
\hline $\begin{array}{l}\text { Los } \\
\text { Angeles, } \\
\text { USA }\end{array}$ & $6-220$ & 13,900 & $3.97 \times 10^{4}+1.12 \times 10^{5} \mathrm{e}^{-0.023 \mathrm{X}}$ & 2.50 & 17.96 & $\begin{array}{l}\text { Zhu et al. } \\
\text { (2002a) }\end{array}$ \\
\hline $\begin{array}{l}\text { Leicester, } \\
\text { UK }\end{array}$ & $5-1,000$ & 1,100 & NA & 0.64 & 58.36 & $\begin{array}{l}\text { Agus et al. } \\
(2007)\end{array}$ \\
\hline $\begin{array}{l}\text { Guildford, } \\
\text { UK }\end{array}$ & $5-560$ & 6,612 & NA & $1.78^{\mathrm{b}}$ & 26.92 & $\begin{array}{l}\text { Present } \\
\text { study }\end{array}$ \\
\hline
\end{tabular}

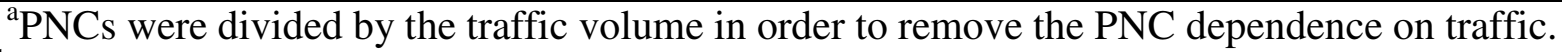

${ }^{\mathrm{b}}$ Field measurements.

\subsubsection{PNCs along the roadside at locations with and without the vegetation barrier}

In order to evaluate the effect of vegetation barrier on the roadside PNCs, the PNC at sampling locations $L_{1}$ and $L_{2}$ are selected for comparison purposes. As expected, the total PNCs were $11 \%$ higher at $L_{2}$ during cross-road winds compared with those at $L_{1}$, mainly due to the presence of vegetation barrier which impeded the particles movement at sampling location $L_{2}$ and resulted in their accumulation. These observations clearly suggest that the hindrance brought by the vegetation barrier helps in reducing the PNC level to reach to the footpath. Under the other wind directions where vegetation barrier is playing no role, the total PNCs at $L_{2}$ were somewhat similar to $L_{1}$, with only $0.25-1.50 \%$ difference, due to near identical dispersion conditions experienced by both locations. Discussions on how much particles were removed by the vegetation barrier are presented in Section 3.2.

\subsection{Influence of vegetation barrier on particles characteristics}

\subsubsection{Influence of vegetation barrier on the shape of PNDs}

Cite this article as: Al-Dabbous, A.N., Kumar, P., 2014. The influence of roadside vegetation barriers on airborne nanoparticles and pedestrians exposure under varying wind condition. Atmospheric Environment 90, 113-124. Online Link: http://dx.doi.org/10.1016/j.atmosenv.2014.03.040 
Figures 2a-c present the average PNDs at all the four sampling locations $\left(L_{1}, L_{2}, L_{3}\right.$ and $L_{4}$ ) during the observed wind directions. The PND remains consistent in their shape for all the cases, but show a general decay pattern with increasing distance from the edge of the road. The rate of this decrease was, however, found to vary during the three wind directions (see Section 3.2.2). The following discussions aim to highlight the influence of vegetation barrier on the PNDs. Therefore the sampling locations $L_{2}, L_{3}$ and $L_{4}$ are included for further analysis since these were at the front, middle and back of the vegetation barrier (see Figure 1).

Similar to $L_{1}$, the PNDs during all the wind directions displayed four peaks at $\sim 5.6,10,27$ and 55-75 $\mathrm{nm}$. Among all, the largest fresh nucleation mode peak occurred at $\sim 5.6 \mathrm{~nm}$, which has average PND values of $3.28 \times 10^{5} \mathrm{~cm}^{-3}, 1.43 \times 10^{5} \mathrm{~cm}^{-3}$ and $6.00 \times 10^{5} \mathrm{~cm}^{-3}$ during crossroad, cross-footpath and along-road winds, respectively. This peak is followed by a slightly smaller peak at $\sim 10 \mathrm{~nm}$ with PND values of $2.01 \times 10^{5} \mathrm{~cm}^{-3}$ for cross-road winds, $1.06 \times 10^{5}$ $\mathrm{cm}^{-3}$ for cross-footpath winds, and $3.01 \times 10^{5} \mathrm{~cm}^{-3}$ for along-road winds. Because of the close proximity of the sampling location to the road (and hence the emissions sources), both the major peaks at 5.6 and $10 \mathrm{~nm}$ are due to the newly formed nucleation mode particles that are originated by the gas-to-particle conversion process (Kulmala et al., 2004; Kumar et al., 2010). The less conspicuous peak at $27 \mathrm{~nm}$ reflects the Aitken mode particles, but their presence was modest compared with nucleation and accumulation mode particles (Table 4). The latter mode was reflected by above- $55 \mathrm{~nm}$ peaks at $75 \mathrm{~nm}$ (with PND value of $1.65 \times 10^{5}$ $\left.\mathrm{cm}^{-3}\right), 55 \mathrm{~nm}\left(1.42 \times 10^{4} \mathrm{~cm}^{-3}\right)$ and $65 \mathrm{~nm}\left(4.27 \times 10^{5} \mathrm{~cm}^{-3}\right)$ for cross-road, cross-footpath and along-road winds, respectively. The trend in the peak PND values followed the similar pattern that was observed at $L_{1}$ during the three wind direction and the likely reasons of these variations are explained in Section 3.1.1. The accumulation mode particles are generally believed to be formed in the combustion chamber (Kittelson et al., 2001). Despite the fact that the nucleation mode particles have larger diffusivity that offer them better chances to deposit on the surfaces of vegetation barrier compared with accumulation mode particles (Hinds, 1999), the consistency in the shape of PNDs and the corresponding GMDs at $L_{2}-L_{4}$ indicate an identical removal effect of vegetation barrier for all size of particles (see Figures 2a-c and Table 4).

\subsubsection{Influence of vegetation barrier on the PNCs}

Cite this article as: Al-Dabbous, A.N., Kumar, P., 2014. The influence of roadside vegetation barriers on airborne nanoparticles and pedestrians exposure under varying wind condition. Atmospheric Environment 90, 113-124. Online Link: $\quad$ http://dx.doi.org/10.1016/j.atmosenv.2014.03.040 
Irrespective of wind directions, the total PNCs at the sampling locations $L_{2}, L_{3}$ and $L_{4}$ were found to decrease gradually with the increasing distance from the edge of the road through the vegetation barrier (see Figure 2). $L_{2}$ had the highest PNCs due to its close proximity to the source (moving vehicles). The highest and lowest PNCs during the crossroad and cross-footpath winds were observed. This trend is expected due to the wind carrying the traffic emissions directly towards and away from the sampling location during the crossroad and cross-footpath winds, respectively.

The total PNCs at the $L_{3}$ and $L_{4}$ were found to be $\sim 71$ and $77 \%$ lesser, respectively, compared with the total PNCs at the $L_{2}\left(6.26 \pm 3.31 \times 10^{4} \mathrm{~cm}^{-3}\right)$ during the cross-footpath winds. This was expected due to the transport of particles by the wind towards the road, away from the sampling location. Likewise, a reduction of $\sim 55$ and $70 \%$ at $L_{4}$ and $L_{3}$, respectively, was observed during along-road winds compared with the PNCs at the $L_{2}$. The resulting wind effect during the along-road winds, which is sum of the wind speed and the wake speed due to traffic, is expected to be the same at all these locations. Higher PNC at the sampling location close to the road and a decreasing pattern away from it is therefore expected.

The above-noted wind directions do not allow us to investigate the particle removal by the vegetation barrier. However, the data collected at $L_{2}, L_{3}$ and $L_{4}$ during the cross-road winds are ideal for this purpose and is therefore considered for further discussion. The total PNCs at $L_{2}$ were measured as $1.99 \pm 1.77 \times 10^{5} \mathrm{~cm}^{-3}$, which were reduced by 14 and $37 \%$ at $L_{3}$ and $L_{4}$, respectively. Numerous field studies have reported substantial increase in traffic-induced pollution close to roads compared with 10's of metre away from the road (Karner et al., 2010 and references therein). The same applies to nanoparticles where studies have found sharp decrease in PNCs with the distance (Zhu et al., 2002a; Fujitani et al., 2012). The presence of densely foliated vegetation barriers are expected to increase this decay further, leading to much lesser PNCs behind the vegetation barrier, due to enhanced turbulence and initial mixing (Bowker et al., 2007) and deposition of particles on tree leaves and bark (AdabtOakland, 2013). Therefore, this decay in PNCs $\left(\mathrm{L}_{2}-\mathrm{L}_{3}\right)$ could possibly be due to the following reasons: (i) dilution due to the atmospheric (wind) and mechanical (traffic and vegetation barrier) turbulence, and (ii) dry deposition of particles on the branches and leaves of the vegetation barrier. The present study design, however, limits our ability to clearly distinguish the decay of PNCs due to dilution or deposition caused by vegetation barrier.

Cite this article as: Al-Dabbous, A.N., Kumar, P., 2014. The influence of roadside vegetation barriers on airborne nanoparticles and pedestrians exposure under varying wind condition. Atmospheric Environment 90, 113-124. Online Link: $\quad$ http://dx.doi.org/10.1016/j.atmosenv.2014.03.040 
Given the much larger traffic speed $\left(\sim 22.3 \mathrm{~m} \mathrm{~s}^{-1}\right)$ compared with the wind speed $\left(\sim 2.90 \mathrm{~m} \mathrm{~s}^{-}\right.$ ${ }^{1}$ ), the effect of the mechanical turbulence on mixing (and hence the dilution) is likely to dominate over the atmospheric turbulence, as found in our earlier field studies of nanoparticles (see, for example, Kumar et al., 2008a). Some of this decrease at $L_{3}$ and $L_{4}$ is certainly due to the dilution as the turbulence levels are expected to decay with the perpendicular distances away from the road, so is the case with the PNCs, and the rest of the PNC losses can be attributed to the dry deposition. One would expect a greater removal of nucleation mode particles by the vegetation barrier compared with the larger sized particles due to their higher diffusivity (Hinds, 1999), but the inspection of PND curves at $L_{2}-L_{4}$ show negligible changes in their shape while moving through the vegetation barrier (see Figure 2). In fact, the PNDs simply move up and down which does not provide conclusive evidence on the effectiveness of the vegetation barrier on removing the nucleation and accumulation mode particles separately. More systematic studies combining field measurements and numerical modelling are needed to study this aspect as well as accurately apportioning the contribution of the dilution and the dry deposition from the overall PNC losses.

\subsection{The respiratory deposited doses}

Following the methodology described in Section 2.4, the computed values of the RDD at different sampling locations during the observed wind directions are presented in Table S4. Figure 3 presents a comprehensive summary of the RDD at all the sampling locations, including front $\left(L_{2}\right)$, middle $\left(L_{3}\right)$ and back $\left(L_{4}\right)$ of the vegetation barrier, and with no vegetation $\left(L_{1}\right)$ using size dependant DF. The overall differences in the RDD between both approaches (using fixed and size-dependent DF) were found to be insignificant ( 3\%) that is similar to reported elsewhere, i.e. $\sim 1.7 \%$ by Joodatnia et al. (2013a). The use of sizedependent DF for RDD calculation is however much more realistic in order to take into account the variations in the PNDs at the different sampling locations. The work of Joodatnia et al. (2013a) demonstrated that the use of fixed DF may underestimate the RDD in case of the majority of inhaled particles is in the nucleation size range. In what follows, the RDD using the size-dependent DF are discussed.

In order to assess the influence of the presence and absence of the vegetation barrier on the exposure, and hence the RDD, the particle number and size distributions measured before (at $L_{2}$ ) and after (at $\left.L_{4}\right)$ the vegetation barrier are chosen for discussion. The RDD vary

Cite this article as: Al-Dabbous, A.N., Kumar, P., 2014. The influence of roadside vegetation barriers on airborne nanoparticles and pedestrians exposure under varying wind condition. Atmospheric Environment 90, 113-124. Online Link: $\quad \underline{\text { http://dx.doi.org/10.1016/j.atmosenv.2014.03.040 }}$ 
substantially between $L_{2}$ and $L_{4}$ during all the wind directions (see Figure 3). The average RDD for male subjects at $L_{2}$ was $3.31 \times 10^{9} \mathrm{~min}^{-1}, 1.31 \times 10^{9} \mathrm{~min}^{-1}$ and $4.15 \times 10^{9} \mathrm{~min}^{-1}$ for cross-road, cross-footpath and along-road winds, respectively. At $L_{4}$, the RDD for male subjects during cross-road, cross-footpath and along-roads winds was $2.11 \times 10^{9} \mathrm{~min}^{-1}$, $2.67 \times 10^{8} \mathrm{~min}^{-1}$ and $1.75 \times 10^{9} \mathrm{~min}^{-1}$, respectively. The effect of vegetation barrier on the RDD for cross-road winds was clearly noticeable since the presence of the vegetation barrier reduced the RDD by $36 \%$ at $L_{4}$ relative to those at $L_{2}$ (see Figure 3 ). Although the lowest RDD at $L_{4}$ was found during the cross-footpath winds, but this was because of the influence of wind carrying the particles away from the $L_{4}$ rather than due to the presence of the vegetation barrier.

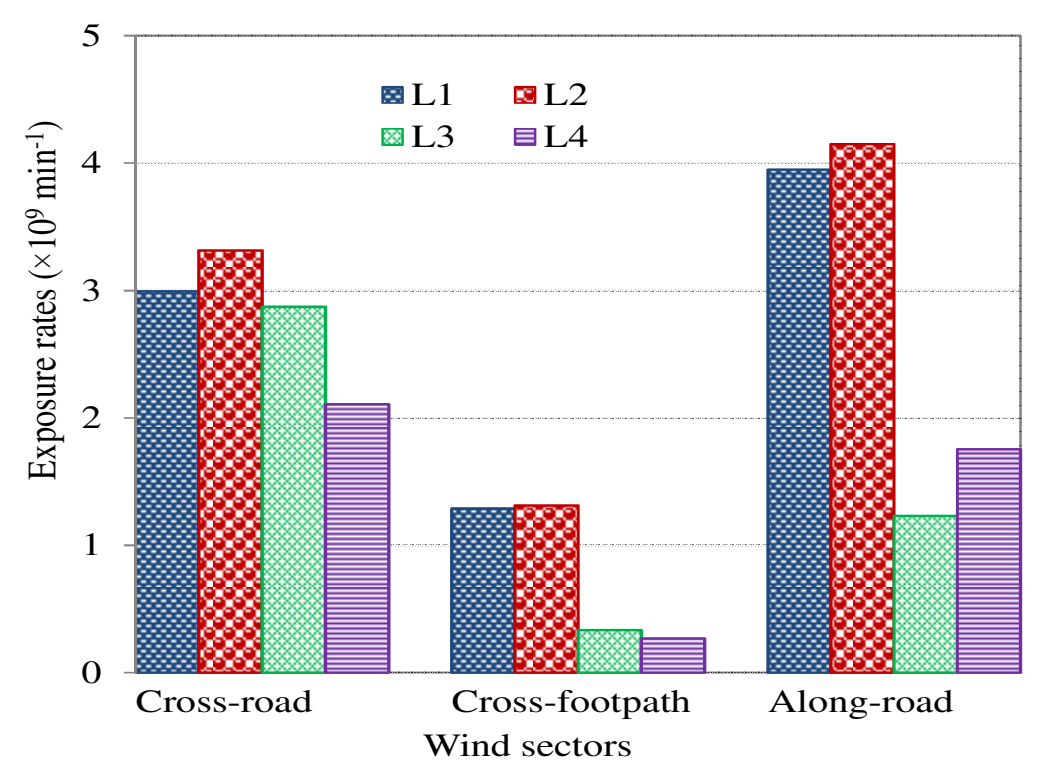

Figure 3: Deposition in human respiratory tract at front $\left(L_{2}\right)$, middle $\left(L_{3}\right)$ and back $\left(L_{4}\right)$ of the vegetation barrier, and with no vegetation $\left(L_{1}\right)$ using size dependant DF for all the three wind directions. Please note that the calculation presented in this figure is for male subjects with light exercise.

Availability of the RDD for direct comparison is limited as there are currently no studies available which have computed the effect of vegetation barriers on the RDD. We have therefore compared the RDD values measured at footpath $\left(L_{4}\right)$ with the other best possible matching studies. To make such comparisons compatible with each other, we have recalculated the RDD measured by Int Panis et al. (2010) from $\# \mathrm{~m}^{-1}$ to $\# \mathrm{~min}^{-1}$ after taking into consideration the route length and journey time. They estimated that the average RDD for male cyclists were $4.63 \times 10^{6} \mathrm{~m}^{-1}\left(1.44 \times 10^{9} \mathrm{~min}^{-1}\right), 1.67 \times 10^{6} \mathrm{~m}^{-1}\left(5.62 \times 10^{8} \mathrm{~min}^{-1}\right)$ and

Cite this article as: Al-Dabbous, A.N., Kumar, P., 2014. The influence of roadside vegetation barriers on airborne nanoparticles and pedestrians exposure under varying wind condition. Atmospheric Environment 90, $113-124$

Online Link: http://dx.doi.org/10.1016/j.atmosenv.2014.03.040 
$0.94 \times 10^{6} \mathrm{~m}^{-1}\left(3.41 \times 10^{8} \mathrm{~min}^{-1}\right)$ in Brussels, Louvain-la-Neuve and Mol, respectively. Kumar et al. (2013) estimated an average RDD as $5.12 \times 10^{8} \mathrm{~min}^{-1}$, varying between $1.95 \times 10^{8}$ and $1.26 \times 10^{9} \mathrm{~min}^{-1}$. These estimates were the average of 45 different roadside sampling locations in a number of European cities. Our RDD during cross-footpath winds at $L_{4}$ falls within the range of those estimated by Kumar et al. (2013) and Int Panis et al. (2010). However, during cross-road and along-road winds, the RDD estimations by Int Panis et al. (2010) and Kumar et al. (2013) were found to be 1.47-4.12 and 1.22-3.42 times lower than those estimated here. This difference was expected due to the contribution of much larger fresh nucleation mode particles at $L_{4}$ during these wind directions (Section 3.1.2) and these particles show greatest respiratory deposition compared with their larger counterparts (ICRP, 1994; Kumar et al., 2014).

\section{SUMMARY AND CONCLUSIONS}

Particle number and size distributions in the 5-560 nm size range were measured using a fast response instrument along a major road in Guildford (Surrey, UK). Measurements were made at four different sampling locations, pseudo-simultaneously, with the help of a 4-way solenoid switching system that was attached to the DMS50 to cover the sampling locations before, middle and after the vegetation barrier, and also at a sampling point with clear opening (i.e. no vegetation). Data were categorised into three wind conditions (i.e. cross-road, cross-footpath and along-road winds) for assessing the effects of vegetation on the PNCs in various size ranges and respiratory deposited doses.

During all the studied wind directions, the PNDs displayed two dominating peaks at 5.6, 10 $\mathrm{nm}$, and a varying peak in the 55-75 $\mathrm{nm}$ range. Comparison of the PNCs measured along the roadside at the sampling locations with $\left(L_{2}\right)$ and without $\left(L_{1}\right)$ the vegetation barrier during cross-road winds show accumulation of PNCs at $L_{2}$ due to the obstruction in free movement of particles by the vegetation barrier. Consequently the PNCs at $L_{2}$ were found to be $\sim 11 \%$ higher than those at $L_{1}$ (Figure 1). Such differences were insignificant during the crossfootpath and along-road winds. Our results also suggest that the presence of vegetation barrier reduced concentrations of nanoparticles during the cross-road winds - this reduction was found to be 14 and $37 \%$ in middle $\left(L_{3}\right)$ and after $\left(L_{4}\right)$ the vegetation barrier from the sampling location that was before the vegetation $\left(L_{2}\right)$. During the cross-footpath and alongroad winds, the PNCs were also found to decrease notably at $L_{3}$ and $L_{4}$ compared with $L_{2}$.

Cite this article as: Al-Dabbous, A.N., Kumar, P., 2014. The influence of roadside vegetation barriers on airborne nanoparticles and pedestrians exposure under varying wind condition. Atmospheric Environment 90, 113-124. Online Link: $\quad$ http://dx.doi.org/10.1016/j.atmosenv.2014.03.040 
However, this decrease is not attributable to the vegetation barrier, but to the advection of emissions away from the sampling location as well as their sweeping along the road during the cross-footpath and along-road winds, respectively.

The differences between the RDD values at $L_{2}$ and $L_{4}$ were highest during the cross-footpath winds (80\%), followed by along-road (58\%) and cross-road (36\%) winds. The lowest RDD values were estimated for $L_{4}\left(2.67 \times 10^{8} \mathrm{~min}^{-1}\right)$ during the cross-footpath winds, indicating a preferable wind direction for footpath users from the exposure point of view. These lower RDD were because of the favourable wind direction that resisted the free movement of fresh nucleation mode particles to the $L_{4}$, but not due to the vegetation barrier. The reduction in the RDD due to the presence of the vegetation barrier can only be seen during cross-road winds. The RDD were found to be reduced by $\sim 36 \%$ at footpath sampling location after vegetation $\left(L_{4} ; 2.11 \times 10^{9} \mathrm{~min}^{-1}\right)$ to those before the vegetation $\left(L_{2} ; 3.31 \times 10^{9} \mathrm{~min}^{-1}\right)$. These findings clearly suggest the mitigation potential of vegetation barriers in limiting the nanoparticle exposure to the near-road footpath dwellers.

There are some explainable limitations of this work. For example, health and security issues as well as practical constraints such as the access to power supply at the site only allowed us to make intermittent measurements during the day times. Whilst results of our measurements provide total reduction in PNCs due to the presence of the vegetation barrier, the design of the study limits our ability to provide definitive conclusions on the proportion of the nanoparticles removed by the vegetation and dilution during the transport of emissions through the barrier. Further studies involving diurnal measurements during the different seasons and on other configurations are encouraged in order to understand the seasonal behaviour and particle mitigation potential of a range of vegetation barriers. Nevertheless, use of an unconventional experimental setup in our study provided profound insight into the mitigation potential and dispersion behaviour of the nanoparticles in the presence of a vegetation barrier. Our findings could assist the urban planners to design appropriate mitigation measures for such nanoparticle-rich environments and the modelling community to facilitate the validation of theoretical models against our measured data.

\section{ACKNOWLEDGEMENTS}

Abdullah N. Al-Dabbous greatly acknowledges the support from the Kuwait Institute for Scientific Research (KISR) for the PhD fellowship. The authors also thank Prof. Alan Cite this article as: Al-Dabbous, A.N., Kumar, P., 2014. The influence of roadside vegetation barriers on airborne nanoparticles and pedestrians exposure under varying wind condition. Atmospheric Environment 90, 113-124. Online Link: $\quad$ http://dx.doi.org/10.1016/j.atmosenv.2014.03.040 
Robins for the valuable support and discussions, Drs. Paul Hayden and Paul Nathan for their help in upgrading the switching system, and the UK Met Office for providing the meteorological data.

\section{REFERENCES}

AdabtOakland, 2013. GP1: vegetative air barrier. http://adaptoakland.org/wpcontent/uploads/2013/05/AO_Greenpaper01_AirBarriers_002.pdf

(Accessed 13/10/2013).

Agus, E.L., Young, D.T., Lingard, J.J.N., Smalley, R.J., Tate, J.E., Goodman, P.S., Tomlin, A.S., 2007. Factors influencing particle number concentrations, size distributions and modal parameters at a roof-level and roadside site in Leicester, UK. Science of The Total Environment 386, 65-82.

Bakand, S., Hayes, A., Dechsakulthorn, F., 2012. Nanoparticles: a review of particle toxicology following inhalation exposure. Inhalation Toxicology 24, 125-135.

Baldauf, R., Jackson, L., Hagler, G.S.W., Isakov, V., McPherson, G., Nowak, D., Cahill, T.A., Zhang, K.M., Bailey, C.R., Cook, J.R., Wood, P., 2011. The role of vegetation in mitigating near-road air quality impacts from traffic emissions. Environmental Manager $30-33$.

Baldauf, R., McPherson, G., Wheaton, L., Zhang, M., Cahill, T., Bailey, C., Hemphill-Fuller, C., Withycombe, E., Titus, K., 2013. Integrating vegetation and green infrastructure into sustainable transportation planning. Transportation News 288, 14-18.

Baldauf, R., Thoma, E., Khlystov, A., Isakov, V., Bowker, G., Long, T., Snow, R., 2008. Impacts of noise barriers on near-road air quality. Atmospheric Environment 42, 75027507.

Bowker, G.E., Baldauf, R., Isakov, V., Khlystov, A., Petersen, W., 2007. The effects of roadside structures on the transport and dispersion of ultrafine particles from highways. Atmospheric Environment 41, 8128-8139.

Brantley, H.L., Hagler, G., Deshmukhc, P., Baldauf, R., 2014. Field assessment of the effects of roadside vegetation on near-road black carbon and particulate matter. Science of The Total Environment 468-469, 120-129.

Buonanno, G., Lall, A.A., Stabile, L., 2009. Temporal size distribution and concentration of particles near a major highway. Atmospheric Environment 43, 1100-1105.

Cite this article as: Al-Dabbous, A.N., Kumar, P., 2014. The influence of roadside vegetation barriers on airborne nanoparticles and pedestrians exposure under varying wind condition. Atmospheric Environment 90, 113-124. Online Link: $\quad$ http://dx.doi.org/10.1016/j.atmosenv.2014.03.040 
Burt, S., Eden, P., 2004. The August 2003 heatwave in the United Kingdom. Part 2-The hottest sites. Weather 59, 239-246.

Buseck, P.R., Adachi, K., 2008. Nanoparticles in the atmosphere. Elements 4, 389-394.

Carpentieri, M., Kumar, P., 2011. Ground-fixed and on-board measurements of nanoparticles in the wake of a moving vehicle. Atmospheric Environment 45, 5837-5852.

Daigle, C.C., Chalupa, D.C., Gibb, F.R., Morrow, P.E., Oberdörster, G., Utell, M.J., Frampton, M.W., 2003. Ultrafine Particle Deposition in Humans During Rest and Exercise. Inhalation Toxicology 15, 539-552.

EC, 2008. Commission Regulation (EC) No 692/2008 of 18 July 2008 implementing and amending Regulation (EC) No 715/2007 of the European Parliament and of the Council on type-approval of motor vehicles with respect to emissions from light passenger and commercial vehicles (Euro 5 and Euro 6) and on access to vehicle repair and maintenance information. Official Journal of the European Union, pp. 1-136.

Fujitani, Y., Kumar, P., Tamura, K., Fushimi, A., Hasegawa, S., Takahashi, K., Tanabe, K., Kobayashi, S., Hirano, S., 2012. Seasonal differences of the atmospheric particle size distribution in a metropolitan area in Japan. Science of The Total Environment 437, 339-347.

Guildford-Borough, 2009. State of Guildford Borough Report.

Hagler, G.S.W., Lin, M.-Y., Khlystov, A., Baldauf, R.W., Isakov, V., Faircloth, J., Jackson, L.E., 2012. Field investigation of roadside vegetative and structural barrier impact on near-road ultrafine particle concentrations under a variety of wind conditions. Science of The Total Environment 419, 7-15.

Heist, D.K., Perry, S.G., Brixey, L.A., 2009. A wind tunnel study of the effect of roadway configurations on the dispersion of traffic-related pollution. Atmospheric Environment $43,5101-5111$.

Hinds, W.C., 1999. Aerosol technology: properties, behaviour and measurement of airborne particles. John Wiley \& Sons, New York.

Hofmann, W., 2011. Modelling inhaled particle deposition in the human lung-A review. Journal of Aerosol Science 42, 693-724.

Hwang, H.-J., Yook, S.-J., Ahn, K.-H., 2011. Experimental investigation of submicron and ultrafine soot particle removal by tree leaves. Atmospheric Environment 45, 69876994.

Cite this article as: Al-Dabbous, A.N., Kumar, P., 2014. The influence of roadside vegetation barriers on airborne nanoparticles and pedestrians exposure under varying wind condition. Atmospheric Environment 90, 113-124. Online Link: $\quad$ http://dx.doi.org/10.1016/j.atmosenv.2014.03.040 
ICRP, 1994. Human respiratory tract model for radiological protection. A report of a task group of the International Commission on Radiological Protection. Annals of the ICRP $24,1-482$.

Int Panis, L., de Geus, B., Vandenbulcke, G., Willems, H., Degraeuwe, B., Bleux, N., Mishra, V., Thomas, I., Meeusen, R., 2010. Exposure to particulate matter in traffic: A comparison of cyclists and car passengers. Atmospheric Environment 44, 2263-2270.

Jones, A.M., Harrison, R.M., Barratt, B., Fuller, G., 2012. A large reduction in airborne particle number concentrations at the time of the introduction of "sulphur free" diesel and the London Low Emission Zone. Atmospheric Environment 50, 129-138.

Joodatnia, P., Kumar, P., Robins, A., 2013a. The behaviour of traffic produced nanoparticles in a car cabin and resulting exposure rates. Atmospheric Environment 65, 40-51.

Joodatnia, P., Kumar, P., Robins, A., 2013b. Fast response sequential measurements and modelling of nanoparticles inside and outside a car cabin. Atmospheric Environment 71, 364-375.

Karner, A.A., Eisinger, D.S., Niemeier, D.A., 2010. Near-roadway air quality: Synthesizing the findings from real-world data. Environmental Science \& Technology 44, 53345344.

Kittelson, D.B., Watts, W.J., Johnson, J.P., 2001. Fine Particle (Nanoparticle) Emissions On Minnesota Highways, Final Report: MN/RC - 2001-12. Minnesota Department of Transportation, pp. 1-87.

Kulmala, M., Vehkamaki, H., Petaja, T., Dal Maso, M., Lauri, A., Kerminen, V.M., Birmili, W., McMurry, P.H., 2004. Formation and growth rates of ultrafine atmospheric particles: A review of observations. Journal of Aerosol Science, 35, 143-176.

Kumar, P., Fennell, P., Britter, R., 2008a. Effect of wind direction and speed on the dispersion of nucleation and accumulation mode particles in an urban street canyon. Science of The Total Environment 402, 82-94.

Kumar, P., Fennell, P., Langley, D., Britter, R., 2008b. Pseudo-simultaneous measurements for the vertical variation of coarse, fine and ultrafine particles in an urban street canyon. Atmospheric Environment 42, 4304-4319.

Kumar, P., Fennell, P., Symonds, J., Britter, R., 2008c. Treatment of losses of ultrafine aerosol particles in long sampling tubes during ambient measurements. Atmospheric Environment 42, 8819-8826.

Cite this article as: Al-Dabbous, A.N., Kumar, P., 2014. The influence of roadside vegetation barriers on airborne nanoparticles and pedestrians exposure under varying wind condition. Atmospheric Environment 90, 113-124. Online Link: $\quad$ http://dx.doi.org/10.1016/j.atmosenv.2014.03.040 
Kumar, P., Robins, A., Britter, R., 2009. Fast response measurements of the dispersion of nanoparticles in a vehicle wake and a street canyon. Atmospheric Environment 43, 6110-6118.

Kumar, P., Robins, A., Vardoulakis, S., Britter, R., 2010. A review of the characteristics of nanoparticles in the urban atmosphere and the prospects for developing regulatory controls. Atmospheric Environment 44, 5035-5052.

Kumar, P., Gurjar, B.R., Nagpure, A.S., Harrison, R.M., 2011a. Preliminary estimates of nanoparticle number emissions from road vehicles in megacity Delhi and associated health impacts. Environmental Science and Technology 45, 5514-5521.

Kumar, P., Ketzel, M., Vardoulakis, S., Pirjola, L., Britter, R., 2011b. Dynamics and dispersion modelling of nanoparticles from road traffic in the urban atmospheric environment - A review. Journal of Aerosol Science 42, 580-603.

Kumar, P., Mulheron, M., Som, C., 2012. Release of ultrafine particles from three simulated building processes. Journal of Nanoparticle Research 14, 771, doi: 10.1007/s11051012-0771-2.

Kumar, P., Morawska, L., Harrison, R., 2013. Nanoparticles in European cities and associated health impacts, in: Viana, M. (Ed.), Urban Air Quality in Europe. Springer Berlin Heidelberg, vol. 26, pp. 339-365. http://dx.doi.org/10.1007/698_2012_161

Kumar, P., Morawska, L., Birmili, W., Paasonen, P., Hu, M., Kulmala, M., Harrison, R.M., Norford, L., Britter, R., 2014. Ultrafine particles in cities. Environment International $66,1-10$.

Lin, M.-Y., Khlystov, A., 2011. Investigation of Ultrafine Particle Deposition to Vegetation Branches in a Wind Tunnel. Aerosol Science and Technology 46, 465-472.

Lin, M., Katul, G.G., Khlystov, A., 2012. A branch scale analytical model for predicting the vegetation collection efficiency of ultrafine particles. Atmospheric Environment 51, 293-302.

Lingard, J.J.N., Agus, E.L., Young, D.T., Andrews, G.E., Tomlin, A.S., 2006. Observations of urban airborne particle number concentrations during rush-hour conditions: analysis of the number based size distributions and modal parameters. Journal of Environmental Monitoring 8, 1203-1203.

Maher, B.A., Ahmed, I.A.M., Davison, B., Karloukovski, V., Clarke, R., 2013. Impact of roadside tree lines on indoor concentrations of traffic-derived particulate matter. Environmental Science \& Technology 47, 13737-13744.

Cite this article as: Al-Dabbous, A.N., Kumar, P., 2014. The influence of roadside vegetation barriers on airborne nanoparticles and pedestrians exposure under varying wind condition. Atmospheric Environment 90, 113-124. Online Link: $\quad$ http://dx.doi.org/10.1016/j.atmosenv.2014.03.040 
Morawska, L., Ristovski, Z., Jayaratne, E.R., Keogh, D.U., Ling, X., 2008. Ambient nano and ultrafine particles from motor vehicle emissions: Characteristics, ambient processing and implications on human exposure. Atmospheric Environment 42, 81138138 .

Petroff, A., Mailliat, A., Amielh, M., Anselmet, F., 2008. Aerosol dry deposition on vegetative canopies. Part II: A new modelling approach and applications. Atmospheric Environment 42, 3654-3683.

Steffens, J.T., Wang, Y.J., Zhang, K.M., 2012. Exploration of effects of a vegetation barrier on particle size distributions in a near-road environment. Atmospheric Environment 50, 120-128.

Stjern, C.W., Stohl, A., Kristjansson, J.E., 2011. Have aerosols affected trends in visibility and precipitation in Europe? J. Geophys. Res. 116, D02212-D02212.

Surrey-i, 2012. First release of 2011 Census data.

Venkatram, A., Isakov, V., Thoma, E., Baldauf, R., 2007. Analysis of air quality data near roadways using a dispersion model. Atmospheric Environment 41, 9481-9497.

Vos, P.E.J., Maiheu, B., Vankerkom, J., Janssen, S., 2013. Improving local air quality in cities: To tree or not to tree? Environmental Pollution 183, 113-122.

Zhu, Y., Hinds, W.C., Kim, S., Shen, S., Sioutas, C., 2002a. Study of ultrafine particles near a major highway with heavy-duty diesel traffic. Atmospheric Environment 36, 43234335 .

Zhu, Y.F., Hinds, W.C., Kim, S., Sioutas, C., 2002b. Concentration and size distribution of ultrafine particles near a major highway. Journal of the Air Waste Management Association 1995 52, 1032-1042.

Cite this article as: Al-Dabbous, A.N., Kumar, P., 2014. The influence of roadside vegetation barriers on airborne nanoparticles and pedestrians exposure under varying wind condition. Atmospheric Environment 90, 113-124. Online Link: $\quad$ http://dx.doi.org/10.1016/j.atmosenv.2014.03.040 


\title{
Supplementary Information
}

\author{
for
}

\section{The influence of roadside vegetation barriers on airborne nanoparticles and pedestrians exposure under varying wind conditions}

\author{
Abdullah N. Al-Dabbous ${ }^{1}$ and Prashant Kumar ${ }^{1,2, *}$ \\ ${ }^{1}$ Department of Civil and Environmental Engineering, Faculty of Engineering and Physical \\ Sciences (FEPS), University of Surrey, Guildford GU2 7XH, United Kingdom \\ ${ }^{2}$ Environmental Flow (EnFlo) Research Centre, FEPS, University of Surrey, Guildford GU2 \\ 7XH, United Kingdom
}

"Corresponding author: Address as above; Tel. +44 1483 682762; Fax: +44 1483 682135;

Email addresses: P.Kumar@ surrey.ac.uk, Prashant.Kumar@ cantab.net

Cite this article as: Al-Dabbous, A.N., Kumar, P., 2014. The influence of roadside vegetation barriers on airborne nanoparticles and pedestrians exposure under varying wind condition. Atmospheric Environment 90, 


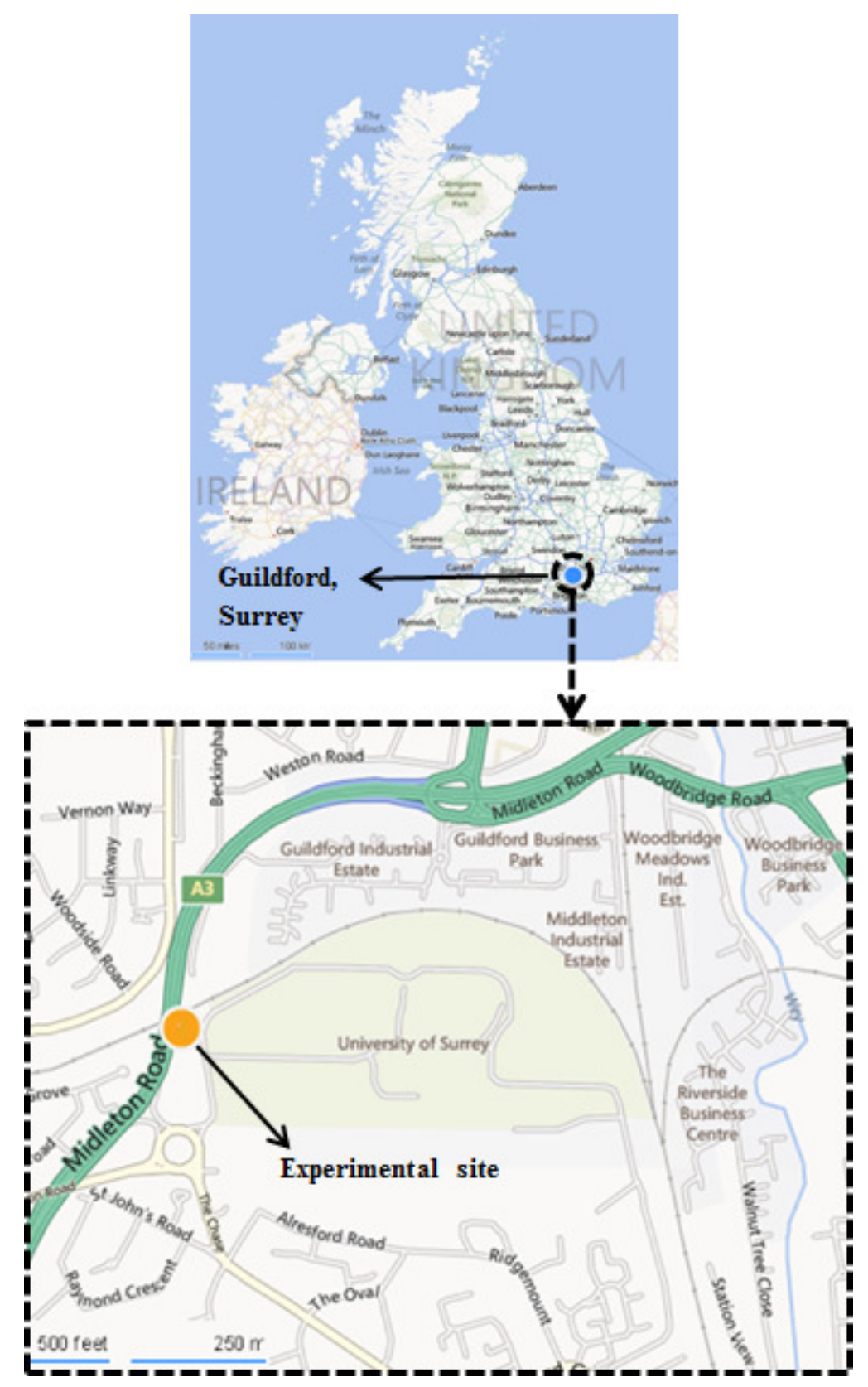

Figure S1: Location of the sampling site.

\section{S1. ESTIMATION OF DEPOSITION FRACTIONS}

For calculating the fixed and size-dependent deposited fraction (DF), the following simplified equations given by Hinds (1999) that are based on ICRP model (ICRP, 1994):

$$
D F=I F\left(0.0587+\frac{0.911}{1+\exp (4.77+1.485 \ln (d p))}+\frac{0.943}{1+\exp (0.508-2.58 \ln (d p))}\right)
$$

Where IF is the inhalable fraction ICRP (1994), and $d_{\mathrm{p}}$ is particle diameter in $\mu \mathrm{m}$.

Cite this article as: Al-Dabbous, A.N., Kumar, P., 2014. The influence of roadside vegetation barriers on airborne nanoparticles and pedestrians exposure under varying wind condition. Atmospheric Environment 90, 113-124. Online Link: http://dx.doi.org/10.1016/j.atmosenv.2014.03.040 


$$
I F=1-0.5\left(1-\frac{1}{1+0.00076 d p^{2.8}}\right)
$$

Using the above equations, the fixed and size-dependent DF is calculated which is respectively shown in Table S3 and Figure S2.

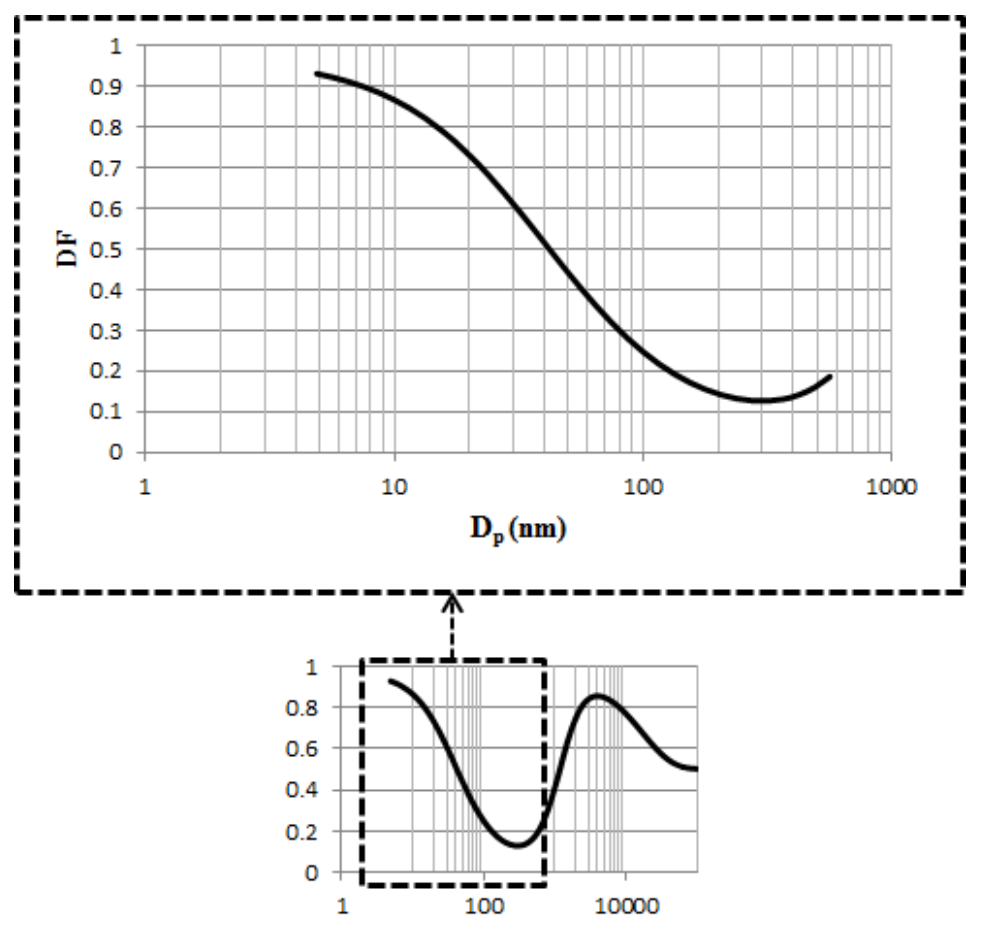

Figure S2: Size-dependant deposition fraction considered in respiratory deposited doses calculations for approach 2 .

Table S1: Measured and corrected particle number concentrations at various distances from the edge of A3 road, presented in three wind conditions.

\begin{tabular}{llllll}
\hline Wind direction & PNCs & \multicolumn{4}{c}{ Sampling locations } \\
\cline { 3 - 6 } & & $L_{1}$ & $L_{2}$ & $L_{3}$ & $L_{4}$ \\
\hline cross-road & Measured & $1.51 \times 10^{5}$ & $1.70 \times 10^{5}$ & $1.46 \times 10^{5}$ & $1.06 \times 10^{5}$ \\
& Corrected & $1.78 \times 10^{5}$ & $1.99 \times 10^{5}$ & $1.71 \times 10^{5}$ & $1.25 \times 10^{5}$ \\
& & & & & \\
cross-footpath & Measured & $4.87 \times 10^{4}$ & $4.96 \times 10^{4}$ & $1.50 \times 10^{4}$ & $1.22 \times 10^{4}$ \\
& Corrected & $6.17 \times 10^{4}$ & $6.26 \times 10^{4}$ & $1.80 \times 10^{4}$ & $1.46 \times 10^{4}$ \\
along-road & Measured & $1.52 \times 10^{5}$ & $1.51 \times 10^{5}$ & $5.00 \times 10^{4}$ & $6.98 \times 10^{4}$ \\
& Corrected & $1.94 \times 10^{5}$ & $1.95 \times 10^{5}$ & $6.10 \times 10^{4}$ & $8.89 \times 10^{4}$ \\
\hline
\end{tabular}

Cite this article as: Al-Dabbous, A.N., Kumar, P., 2014. The influence of roadside vegetation barriers on airborne nanoparticles and pedestrians exposure under varying wind condition. Atmospheric Environment 90, 113-124. Online Link: http://dx.doi.org/10.1016/j.atmosenv.2014.03.040 
Table S2: Fixed deposition fraction considered in respiratory deposited doses calculations for approach 1.

\begin{tabular}{lllllll}
\hline Wind status & & \multicolumn{5}{c}{ Sampling locations } \\
\cline { 3 - 7 } & & $L_{1}$ & $L_{2}$ & $L_{3}$ & $L_{4}$ & Avg. \\
\hline Cross-road & GMD (nm) & 22.53 & 23.09 & 22.71 & 22.20 & 22.63 \\
& DF & 0.70 & 0.70 & 0.70 & 0.70 & 0.70 \\
& & & & & & \\
Cross-footpath & GMD (nm) & 13.33 & 12.33 & 17.11 & 17.97 & 15.18 \\
& DF & 0.82 & 0.84 & 0.77 & 0.76 & 0.80 \\
Along-road & GMD (nm) & 11.64 & 11.28 & 15.77 & 11.94 & 13.40 \\
& DF & 0.84 & 0.85 & 0.79 & 0.84 & 0.83 \\
\hline
\end{tabular}

Table S3: PNC and GMD at the background location collected on 24/03/2013.

\begin{tabular}{lll}
\hline $\mathrm{N}_{5-560}$ & $\# \mathrm{~cm}^{-3}$ & $1.31 \pm 0.57 \times 10^{4}$ \\
$\mathrm{~N}_{5-30}$ & $\# \mathrm{~cm}^{-3}$ & $6.48 \times 10^{3}$ \\
$\mathrm{~N}_{30-100}$ & $\# \mathrm{~cm}^{-3}$ & $3.76 \times 10^{3}$ \\
$\mathrm{~N}_{100-300}$ & $\# \mathrm{~cm}^{-3}$ & $2.84 \times 10^{3}$ \\
$\mathrm{~N}_{300-560}$ & $\# \mathrm{~cm}^{-3}$ & 63.39 \\
$\mathrm{Max}$ & $\# \mathrm{~cm}^{-3}$ & $6.30 \times 10^{4}$ \\
$\mathrm{Min}$ & $\# \mathrm{~cm}^{-3}$ & $1.28 \times 10^{3}$ \\
GMD & $\mathrm{nm}$ & 28.64 \\
\hline
\end{tabular}

Table S4: Deposition in human respiratory tract for all sampling locations, presented in three wind conditions.

\begin{tabular}{llllll}
\hline Wind status & DF approach & \multicolumn{4}{l}{ Sampling locations } \\
\cline { 3 - 5 } & & L1 & L2 & L3 & L4 \\
\hline Cross-road & Fixed & $3.10 \times 10^{9}$ & $3.44 \times 10^{9}$ & $2.97 \times 10^{9}$ & $2.19 \times 10^{9}$ \\
& Size-dependant & $2.99 \times 10^{9}$ & $3.31 \times 10^{9}$ & $2.87 \times 10^{9}$ & $2.11 \times 10^{9}$ \\
& & & & \\
Cross-footpath & Fixed & $1.27 \times 10^{9}$ & $1.31 \times 10^{9}$ & $3.46 \times 10^{8}$ & $2.76 \times 10^{8}$ \\
& Size-dependant & $1.29 \times 10^{9}$ & $1.31 \times 10^{9}$ & $3.34 \times 10^{8}$ & $2.67 \times 10^{8}$ \\
& & & & \\
Along-road & Fixed & $4.11 \times 10^{9}$ & $4.14 \times 10^{9}$ & $1.20 \times 10^{9}$ & $1.87 \times 10^{9}$ \\
& Size-dependant & $3.95 \times 10^{9}$ & $4.15 \times 10^{9}$ & $1.23 \times 10^{9}$ & $1.75 \times 10^{9}$ \\
\hline
\end{tabular}

Note: All calculation presented in this table is for male with light exercise.

Cite this article as: Al-Dabbous, A.N., Kumar, P., 2014. The influence of roadside vegetation barriers on airborne nanoparticles and pedestrians exposure under varying wind condition. Atmospheric Environment 90, 113-124. Online Link: http://dx.doi.org/10.1016/j.atmosenv.2014.03.040 